Published in final edited form as:

Genes Immun. 2019 April ; 20(4): 308-326. doi:10.1038/s41435-017-0006-8.

\title{
High Resolution HLA Analysis Reveals Independent Class I Haplotypes and Amino-Acid Motifs Protective for Multiple Sclerosis
}

\author{
Steven J. Mack ${ }^{1}$, Julia Udell ${ }^{2}$, Franziska Cohen ${ }^{1}$, Kazutoyo Osoegawa ${ }^{3}$, Sharon K. \\ Hawbecker $^{1}$, David A. Noonan ${ }^{1}$, Martha B. Ladner ${ }^{1}$, Damian Goodridge ${ }^{4}$, Elizabeth A. \\ Trachtenberg $^{1}$, Jorge R. Oksenberg ${ }^{5}$, and Henry A. Erlich ${ }^{1}$ \\ ${ }^{1}$ Center for Genetics, Children's Hospital Oakland Research Institute, Oakland CA, USA \\ 2University of Minnesota Twin Cities, Minneapolis MN, USA \\ ${ }^{3}$ Histocompatibility, Immunogenetics \& Disease Profiling Laboratory, Stanford Blood Center, Palo \\ Alto CA, USA \\ ${ }^{4}$ Illumina, San Diego CA, USA \\ ${ }^{5}$ Department of Neurology, University of California, San Francisco CA, USA
}

\section{Abstract}

\begin{abstract}
We investigated association between $H L A$ class I and class II alleles and haplotypes, and KIR loci and their HLA class I ligands, with multiple sclerosis (MS) in 412 European-American MS patients and 419 ethnically-matched controls, using next generation sequencing. The $D R B 1 * 15: 01 \sim D Q B 1 * 06: 02$ haplotype was highly predisposing (odds ratio $(\mathrm{OR})=3.98 ; 95 \%$ confidence interval $(\mathrm{CI})=3-5.31 ; \mathrm{p}$-value $(\mathrm{p})=2.22 \mathrm{E}-16)$, as was $D R B 1 * 03: 01 \sim D Q B 1 * 02: 01$ $(\mathrm{OR}=1.63 ; \mathrm{CI}=1.19-2.24 ; \mathrm{p}=1.41 \mathrm{E}-03)$. Hardy-Weinberg $(\mathrm{HW})$ analysis in MS patients revealed a significant $D R B 1 * 03: 01 \sim D Q B 1 * 02: 01$ homozyote excess (15 observed, 8.6 expected; $\mathrm{p}$ $=0.016)$. The $\mathrm{OR}$ for this genotype $(5.27 ; \mathrm{CI}=1.47-28.52 ; \mathrm{p}=0.0036)$ suggests a recessive MS risk model. Controls displayed no HW deviations. The $C^{*} 03: 04 \sim B * 40: 01$ haplotype (OR $=0.27$; $\mathrm{CI}=0.14-0.51 ; \mathrm{p}=6.76 \mathrm{E}-06)$ was highly protective for MS, especially in haplotypes with $A * 02: 01(\mathrm{OR}=0.15 ; \mathrm{CI}=0.04-0.45 ; \mathrm{p}=6.51 \mathrm{E}-05)$. By itself, $A^{*} 02: 01$ is moderately protective, $(\mathrm{OR}=0.69 ; \mathrm{CI}=0.54-0.87 ; \mathrm{p}=1.46 \mathrm{E}-03)$, and haplotypes of $A^{*} 02: 01$ with the HLA-B Thr80 $\mathrm{Bw} 4$ variant $(\mathrm{Bw} 4 \mathrm{~T})$ more so $(\mathrm{OR}=0.53 ; \mathrm{CI}=0.35-0.78 ; \mathrm{p}=7.55 \mathrm{E}-04)$. Protective associations with the Bw4 KIR ligand resulted from linkage disequilibrium (LD) with $D R B 1 * 15: 01$, but the Bw4T variant was protective $(\mathrm{OR}=0.64 ; \mathrm{CI}=0.49-0.82 ; \mathrm{p}=3.37 \mathrm{E}-04)$ independent of $\mathrm{LD}$ with $D R B 1 * 15: 01$. The Bw4I variant was not associated with MS. Overall, we find specific class I $H L A$ polymorphisms to be protective for MS, independent of the strong predisposition conferred by $D R B 1 * 15: 01$.
\end{abstract}

\footnotetext{
Users may view, print, copy, and download text and data-mine the content in such documents, for the purposes of academic research, subject always to the full Conditions of use: http://www.nature.com/authors/editorial_policies/license.html\#terms

Corresponding Author: Steven J. Mack, Children's Hospital Oakland Research Institute, 5700 Martin Luther King Junior Way, Oakland. CA 94501, sjmack@ chori.org.

Conflicts of Interest

All authors declare that they have no competing financial interests in relation to the work described.
} 


\section{Introduction}

Multiple sclerosis (MS) is a chronic inflammatory disease of the central nervous system with well-documented genetic contributions to its pathogenesis ${ }^{1}$. Genome wide association studies have implicated $>100$ loci in MS risk ${ }^{1}$. The strongest genetic associations with MS are with specific alleles at the HLA loci, in the Major Histocompatibility Complex (MHC) on chromosome 6p21. In particular, $H L A-D R B 1 * 15: 01$ is the strongest genetic determinant of MS; this association has been very well-established in a variety of studies and populations $^{2-4}$. HLA-DRB1 allelic heterogeneity in MS risk has been described ${ }^{5-16}$, but the role of genetic variation at the other HLA loci has been less clearly defined, due, in part, to the extensive linkage disequilibrium (LD) among the alleles at these loci. The MHC includes $\sim 165$ closely-linked genes, roughly half of which have immune-related functions ${ }^{17}$, and large-scale SNP screening of the MHC has identified at least one non-HLA MS association in the so-called class III region ${ }^{14}$. Using recently developed next generation sequencing (NGS) assays, we investigated the association of HLA class I and class II alleles with MS. NGS also facilitates the association analysis of the DRB3, DRB4 and DRB5 loci (DRB3/4/5). These loci display strong LD with specific DRB1 allele families ${ }^{18}$, and may modulate autoimmune disease associations attributed to the DRB1 locus ${ }^{19}$ and display DRB1-independent associations ${ }^{20,21}$.

HLA disease associations are typically interpreted in terms of peptide binding and presentation driving specific adaptive immune responses, but class I epitopes serve as ligands for the killer immunoglobulin-like receptors (KIR) on natural killer (NK) cells, key elements in innate immunity ${ }^{22,23}$ and possible contributors to MS pathogenesis. While the precise role of innate immunity in MS pathogenesis is unclear, NK cells may contribute to MS indirectly via immunoregulatory activity, or directly through cytotoxicity of selftissues $^{24-27}$.

KIR epitope ligands are encoded by class I amino acid positions 77 and 80 ; variants at these positions define the HLA-C $\mathrm{C} 1$ and $\mathrm{C} 2$ ligands $^{28}{ }^{29}$, the HLA-A A3/A11 ligand, and the Bw4 ligand of HLA-B and some HLA-A molecules ${ }^{30,31}$. Encoded by genes on 19q13.4, inhibitory and stimulatory KIRs regulate the cytolytic killing and cytokine secretion of NK cells. The $K I R$ gene complex is characterized by extensive gene content variation and allelic diversity; KIR haplotypes have been classified into two broad categories: KIR $A$ (nine genes with primarily inhibitory functions) and $K I R B$ (14 genes with inhibitory and stimulatory functions). The $\mathrm{C} 1$ ligand is recognized by the inhibitory KIR2DL2 and KIR2DL3 receptors, C2 by KIR2DL1 ${ }^{29}$, Bw4 by KIR3DL1 ${ }^{32}$, and A3/11 by KIR3DL2 ${ }^{33}$. The stimulatory KIR2DS1 $1^{34,35}$ and KIR2DS2 receptors are thought to bind to C2 and C1, respectively ${ }^{36}$; KIR2DS4 receptors bind strongly to A11 and weakly to $\mathrm{C} 1$ and $\mathrm{C} 2^{37}$.

$K I R$ polymorphism has also been implicated in predisposition to many diseases, including $\mathrm{MS}^{38-43}$. The presence of Bw4, the ligand for KIR KIR3DL1, was protective for MS in a Norwegian cohort ${ }^{38}$ and, more recently, the combination of KIR3DL1 and Bw4 was protective in a study of African-American patients and controls ${ }^{44}$. Disease association analyses of KIR variation in the context of the HLA ligand require adjustment for LD 
between the HLA ligands, and specific disease associated HLA alleles. Using a MALDITOF mass spectrophotometer assay for KIR locus presence/absence and a NGS assay for HLA class I and class II alleles, we explored the association of specific KIR/HLA ligand combinations in a group of 412 patients of non-Hispanic European ancestry and 419 ethnically matched controls. We address the confounding issue of LD in these association analyses using the strategy of stratification, analyzing those strata of the data in which an associated allele is present separately from those in which it is absent.

\section{Results}

We initially examined the association of alleles at individual $H L A$ loci. Due to the very high LD between the $D R B 1$ and $D Q B 1$ loci, and the $H L A-C$ and $-B$ loci, each locus pair (DRB1 DQB1 and $C \sim B$ ) haplotype was analyzed as a "super-locus" (Tables 1, 2, 3 and Supplementary Table S1). With the exception of $D P B 1$, all loci and super-loci displayed significant locus level heterogeneity between MS patients and controls (Table 1).

\subsection{HLA Class II Associations}

Table 2 shows the association of $D R B 1 \sim D Q B 1$ haplotypes and of $D P B 1$ alleles. As extensively documented in previous studies ${ }^{4,45,46}, D R B 1 * 15: 01 \sim D Q B 1 * 06: 02$ confers very high disease risk in this population $(\mathrm{OR}=3.98$; $\mathrm{p}$-value $(\mathrm{p})=<2.22 \mathrm{E}-16)$. We note that the other relatively common $D R 2$ (including $D R 15$ and $D R 16$ alleles) haplotype in this population, $D R B 1 * 16: 01 \sim D Q B 1 * 05: 02$, does not confer MS risk $(\mathrm{OR}=1.0 ; \mathrm{p}=0.95)$ in this dataset. Association studies of African-American populations, in which the LD patterns differ and the $D Q B 1 * 06: 02$ allele is often found on non- $D R B 1 * 15$ haplotypes, indicate that it is $D R B 1 * 15: 01$ and not $D Q B 1 * 06: 02$ that confers MS risk ${ }^{44,47}$. Given the strength of the $D R B 1 * 15: 01$ association with MS, all observed associations (class I alleles or HLA ligands) should be examined in light of potential LD with $D R B 1 * 15: 01$.

The other significantly associated susceptible $D R B 1 \sim D Q B 1$ haplotype in this dataset is $D R B 1 * 03: 01 \sim D Q B 1 * 02: 01(\mathrm{OR}=1.63 ; \mathrm{p}=1.41 \mathrm{E}-03)$, as previously reported ${ }^{5,6}$. The $D R B 1 * 04: 05, * 08: 01$, and $* 13: 03$ alleles, previously reported to be associated with MS ${ }^{7-16}$ were not associated in this data set. $D R B 1{ }^{*} 04: 05$ and $* 08: 01$ are found on haplotypes with different $D Q B 1$ alleles in European and East Asian populations. The low frequency of the $D R B 1 * 13: 03 \sim D Q B 1 * 03: 01$ haplotype in this data set $(\mathrm{f}=0.014$ in controls and 0.02 in cases) may explain the lack of statistical significance for this association $(\mathrm{OR}=1.37 ; \mathrm{CI}=$ $0.6-3.19 ; \mathrm{p}=0.412$ ). The frequency of $D R B 1 * 04: 05$ haplotypes was very low, and these haplotypes were "binned" (Supplementary Table S1). Counts, frequencies and summary statistics for all detected alleles and haplotypes are included in Supplementary Table S2.

$D R B 1 * 01: 01 \sim D Q B 1 * 05: 01(\mathrm{OR}=0.41 ; \mathrm{p}=9.57 \mathrm{E}-06), D R B 1 * 04: 01 \sim D Q B 1 * 03: 01(\mathrm{OR}=$ $0.4 ; \mathrm{p}=1.24 \mathrm{E}-03), D R B 1 * 14: 01 \sim D Q B 1 * 05: 03(\mathrm{OR}=0.42 ; \mathrm{p}=0.038)$ and $D R B 1 * 07: 01 \sim D Q B 1 * 02: 02(\mathrm{OR}=0.55 ; \mathrm{p}=0.0014)$ were significantly protective for MS. The $D R B 1 * 01: 01 \sim D Q B 1 * 05: 01$ haplotype is known to include the $D Q A 1 * 01: 01$ allele ${ }^{48-52}$, which, along with $D R B 1 * 01: 01$, was recently shown to be protective for MS in the presence of $D R B 1 * 15: 01^{53}$. While no $D R B 1 \sim D Q B 1$ haplotypes in our study displayed MS associations in the $D R B 1 * 15: 01$-positive stratum (Supplementary Table S3), 
$D R B 1 * 01: 01 \sim D Q B 1 * 05: 01$ remained protective in the $D R B 1 * 15: 01$-negative stratum (OR $=0.57 ; \mathrm{p}=1.9 \mathrm{E}-02)$. The $D R B 1 * 14: 01$ protective effect has been previously reported ${ }^{54-56}$. No individual $D P B 1$ alleles were associated with MS in this data set.

The clonal nature of NGS allows the analysis of the secondary $D R B$ loci $(D R B 3 / 4 / 5)$. Because all $D R B 1 * 15: 01 \sim D Q B 1 * 06: 02$ haplotypes carried the $D R B 5^{*} 01: 01$ allele, and all $D R B 1 * 16: 01 \sim D Q B 1 * 05: 02$ haplotypes carried the $D R B 5^{*} 02: 02$ allele, the role of allelic variation at DRB5 could not be assessed in this dataset. However, the predisposing $D R B 1 * 03: 01 \sim D Q B 1 * 02: 01$ haplotype carries either $D R B 3 * 01: 01$ or *02:02. A recent study of type 1 diabetes ${ }^{19}$ showed that the $D R B 1 * 03: 01$ haplotypes carrying $D R B 3 * 02: 02$ conferred greater risk than did those carrying $D R B 3^{*} 01: 01$. For MS, the allelic variation in $D R B 3$, appeared to affect the risk conferred by $D R B 1^{*} 03: 01$ haplotypes based on this modest sample set (15 MS patients, 3 controls) but this effect was not significant. The OR for $D R B 1 * 03: 01$ homozygotes homozygous for $D R B 3 * 01$ :01 was $3.64(\mathrm{CI}=0.69-36.1)$, whereas the OR for $D R B 1 * 03: 01$ homozygotes that carried $D R B 3^{*} 02: 02$ was $8.36(\mathrm{CI}=$ 1.1-371.2). Testing whether the point estimates for these ORs are significantly different will require a larger sample set. We note that $A * 30: 02$ and $B * 18: 01$, alleles in strong LD with $D R B 1{ }^{*} 03: 01 \sim D R B 3 * 02: 02$ haplotypes $^{19}$, are associated with MS (Table 3).

\subsection{Protective Association of $A^{\star} 02: 01$}

In the association analyses of the class I loci (Table 3), $H L A-A * 02: 01$ appears protective $(\mathrm{OR}=0.69 ; \mathrm{p}=1.46 \mathrm{E}-03)$, as previously reported ${ }^{57-62}$. After stratifying the data to account for negative LD with $D R B 1 * 15: 01$ (Table 4), $A * 02: 01$ on haplotypes lacking $D R B 1 * 15: 01$ remains protective $(\mathrm{OR}=0.48 ; \mathrm{p}=1.1 \mathrm{E}-08)$.

Further, the ORs of three common extended $A \sim C \sim B \sim D R B 1 \sim D Q B 1 \sim D P B 1$ haplotypes, all bearing $D R B 1^{*} 15: 01$ and differing only in the $H L A$ - $A$ allele, indicate that the presence of $A * 02: 01$ can reduce the risk conferred by $D R B 1 * 15: 01$ (Table 5). The OR conferred by the extended $C * 07: 02 \sim B * 07: 02 \sim D R B 1 * 15: 01 \sim D Q B 1 * 06: 02 \sim D P B 1 * 04: 01$ haplotype bearing $A * 02: 01$ is lower $(\mathrm{OR}=1.65)$ than the $\mathrm{OR}$ for the same haplotype bearing $A * 03: 01(\mathrm{OR}=$ $2.83)$ or $A * 24: 02(\mathrm{OR}=4.48)$. This protective effect of $A * 02: 01$ is not simply a haplotype effect. The modification of $D R B 1$-mediated risk by $A * 02: 01$ can also be assessed by stratifying the data based on the presence of $A * 02: 01$ (Table 6); these observations suggest that $A^{*} 02: 01$ in cis or in trans can decrease the OR of other $D R B 1 \sim D Q B 1$ haplotypes.

\subsection{Associated C B haplotypes}

For $C \sim B$ haplotypes (Table 3), $C^{*}$ 07:02 $B^{*} 07: 02$ is associated strongly with MS (OR = $1.99 ; \mathrm{p}=8.8 \mathrm{E}-07)$; however, this association reflects the strong LD between this haplotype and the predisposing $D R B 1 * 15: 01$ allele ( $\mathrm{d}^{\prime}{ }_{\mathrm{ij}}=0.71$ in MS patients, and 0.52 in controls). Two different $C \sim B$ haplotypes display a protective association in this data set. As previously reported $^{60,63,64}, C^{*} 05: 01 \sim B^{*} 44: 02$ is modestly protective $(\mathrm{OR}=0.65 ; \mathrm{p}=0.043) . B^{*} 44: 02$ is rarely found with any other $H L A-C$ allele, while the $C^{*} 05: 01 \sim B^{*} 18: 01$ haplotype is clearly not protective $(\mathrm{OR}=2.07 ; \mathrm{CI}=0.88-5.25 ; \mathrm{p}=0.71)$, suggesting that $B * 44: 02$ may be responsible for the observed modest association for this haplotype. 
In addition, the $C^{*} 03: 04 \sim B^{*} 40: 01$ haplotype (OR $=0.27 ; \mathrm{p}=6.76 \mathrm{E}-06$ ) shows a strong protective association. This protective $C \sim B$ haplotype is in LD with the protective $A * 02: 01$ allele, and this three-locus haplotype (Table 4 ) is even more strongly protective ( $\mathrm{OR}=0.15$; $\mathrm{CI}=0.04-0.45 ; \mathrm{p}=6.5 \mathrm{E}-05)$.

The cALD measures $W_{H L A-A / H L A-C \sim H L A-B}$ and $W_{H L A-C \sim H L A-B / H L A-A}$ are 0.6 and 0.42 in cases, and 0.6 and 0.39 in controls, respectively, indicating more variation of $C \sim B$ haplotypes relative to $H L A-A$ alleles, than in $H L A-A$ alleles relative to $C \sim B$ haplotypes; the intermediate level of LD between $A^{*} 02: 01$ and the $C^{*} 03: 04 \sim B^{*} 40: 01$ haplotype (d' ${ }_{\mathrm{ij}}=0.11$ in MS patients and 0.34 in controls) suggests that the strong protective association for the $A^{*}$ 02:01 $C^{*} 03: 04 \sim B^{*} 40: 01$ haplotype results from the combination of these three alleles, and not $\mathrm{LD}$ with a single protective locus. $C^{*} 03: 04 \sim B^{*} 40: 01$ remains protective in the absence of $A * 02: 01$ ( $\mathrm{OR}=0.42 ; \mathrm{p}=0.018$ ), and $A * 02: 01$ is modestly protective in the absence of $C^{*} 03: 04 \sim B^{*} 40: 01(\mathrm{OR}=0.79 ; \mathrm{p}=0.048)$, suggesting that the observed protective association for the $A * 02: 01$ allele is not due entirely to LD with $C^{*} 03: 04 \sim B^{*} 40: 01$.

\subsubsection{Impact of DRB1* 15:01 Predisposition on $C^{\star}$ 03:04 B*40:01 Association-} The highly protective $C^{*} 03: 04 \sim B^{*} 40: 01$ haplotype is in negative LD with the highly predisposing $D R B 1 * 15: 01$ allele $\left(\mathrm{d}^{\prime}{ }_{\mathrm{ij}}=-1\right)$; no $C^{*} 03: 04 \sim B^{*} 40$ :01-bearing haplotypes carry $D R B 1 * 15: 01$. In principle, this negative LD with $D R B 1 * 15: 01$ might account for the protective associations observed for $A^{*} 02: 01$ and $C^{*} 03: 04 \sim B^{*} 40: 01$. We applied stratification analyses (Table 4 ) to determine if this LD pattern could account for the observed protective association of this $C \sim B$ haplotype. In the stratum lacking $D R B 1 * 15: 01$, the protective association of $C^{*} 03: 04 \sim B^{*} 40: 01$ is even stronger $(\mathrm{OR}=0.29 ; \mathrm{CI}=0.15-0.55$; $\mathrm{p}=2.45 \mathrm{E}-05$ ), so the protective association cannot be attributed simply to negative $\mathrm{LD}$ with the highly predisposing $D R B 1 * 15: 01$. In individuals carrying $D R B 1 * 15: 01$, the presence of the $C^{*} 03: 04 \sim B^{*} 40: 01$ haplotype on the other chromosome reduces $\mathrm{MS}$ risk $(\mathrm{OR}=1.37 ; \mathrm{p}=$ 0.57 ) compared to all other $C-B$ haplotypes ( $\mathrm{OR}=5.06 ; \mathrm{p}=3.21 \mathrm{E}-13$ ) (Table 6). The only other significant associations in this $D R B 1 * 15: 01$-negative stratum are $C^{*} 05: 01 \sim B^{*} 18: 01$ $(\mathrm{OR}=2.87 ; \mathrm{p}=0.01)$ and $C^{*} 07: 01 \sim B^{*} 08: 01(\mathrm{OR}=1.98 ; \mathrm{p}=0.0004)$ but these are both due to LD with the predisposing $D R B 1 * 03: 01\left(\mathrm{~d}^{\prime}{ }_{\mathrm{ij}}=0.87\right.$ and 0.72 in cases, and 0.51 and 0.69 in controls, respectively). $C^{*} 03: 04 \sim B^{*} 40: 01$ remained protective in the $D R B 1 * 03: 01$ negative stratum $(\mathrm{OR}=0.32)$ (data not shown).

\subsection{Hardy-Weinberg Equilibrium Analyses}

The analysis of Hardy-Weinberg equilibrium (HWE) among controls can serve as a test of genotyping and sampling validity, while deviations from HWE among cases can, potentially, reveal patterns of disease association. Adherence to HWE expectations is a requirement for control groups in case-control studies. Among those loci that showed a significant MS association ( $H L A-A,-B,-C, D R B 1, D Q B 1)$, no deviation from HWE was observed among controls (data not shown), including HWE analysis for $D R B 1 \sim D Q B 1$ haplotypes. While studies of HLA diversity in the US population have identified varying degrees of population stratification among non-Hispanic European Americans ${ }^{65}$, 66, these Hardy-Weinberg analyses reveal no significant population stratification in this cohort. 
Among MS patients, highly significant deviations from HWE were seen for genotypes of $D R \sim D Q$ haplotypes $(\mathrm{p}=0.0027)$. The two most common genotypes of $D R B 1 \sim D Q B 1$ haplotypes that contributed to this deviation were $D R B 1 * 03: 01 \sim D Q B 1 * 02: 01$ homozygotes (15 observed, 8.6 expected; $\mathrm{p}=0.016$ ) and $D R B 1 * 07: 01 \sim D Q B 1 * 03: 03+D R B 1 * 15: 01 \sim D Q B 1 * 06: 02$ heterozygotes (10 observed, 5.3 expected; $\mathrm{p}=0.0078$ ), both observed more often than expected among cases. The excess of $D R B 1 * 03$ :01 homozygotes among cases suggests a recessive model for MS risk. Consistent with this interpretation of the HWE deviation, the OR for the homozygous $D R B 1 * 03: 01 \sim D Q B 1 * 02: 01$ genotype is $5.27(\mathrm{p}=0.0037)$ compared to $D R B 1 * 03: 01 \sim D Q B 1 * 02: 01+D R \sim D Q * X(\mathrm{OR}=0.74 ; \mathrm{p}=0.13)$, where $D R \sim D Q * X$ is any haplotype that does not include $D R B 1 * 15: 01$ or $D R B 1 * 03: 01$. The OR for this $D R B 1 * 03: 01 \sim D Q B 1 * 02: 01$ homozygote is close to that for $D R B 1 * 03: 01 \sim D Q B 1 * 02: 01+D R B 1 * 15: 01 \sim D Q B 1 * 06: 02(\mathrm{OR}=5.55 ; \mathrm{p}=1.32 \mathrm{E}-06)$ and $D R B 1 * 15: 01 \sim D Q B 1 * 06: 02+D R B 1 * 15: 01 \sim D Q B 1 * 06: 02$ homozygote $(\mathrm{OR}=7.6 ; \mathrm{p}=1.13 \mathrm{E}$ $-05)$.

The excess of observed $D R B 1 * 07: 01 \sim D Q B 1 * 03: 03+D R B 1 * 15: 01 \sim D Q B 1 * 06: 02$ genotypes among cases suggests that the susceptibility conferred by the $D R B 1 * 15: 01$ haplotype may be "dominant" over the protection conferred by the $D R B 1 * 07: 01$ haplotype. The expected number of cases in the HWE analysis is based on the protective effect of the $D R B 1 * 07: 01 \sim D Q B 1 * 03: 03$ haplotype over all genotype combinations.

\subsection{Association analysis of KIR and HLA ligands}

2.5.1 HLA Ligands-Association analyses for the presence/absence of the KIR loci and their HLA ligands are shown in Table 7 and Supplementary Table S4. As previously reported $^{38}$ the HLA ligand Bw4 (Thr or Ile at HLA-B amino-acid position 80 ) is negatively associated with MS (Table 7A; OR $=0.62 ; \mathrm{p}=5.95 \mathrm{E}-04$ ). The $\mathrm{OR}$ for $\mathrm{Bw} 4 / \mathrm{Bw} 4$ is 0.63 and for $\mathrm{Bw} 6 / \mathrm{Bw} 6$ is 1.61. The observed protective effect of $\mathrm{Bw} 4+$ alone, however, may be attributed, in part, to negative LD with the highly predisposing $D R B 1 * 15: 01$; when the data are stratified on the presence of $D R B 1 * 15: 01$ (Table 7B), the statistical significance of the Bw4+ effect is diminished in the stratum missing $D R B 1 * 15: 01$ ( $\mathrm{OR}=0.72 ; \mathrm{p}=0.08$ ). This interpretation suggests that the observed $\mathrm{Bw} 4$ protective association with MS is not necessarily due to the Bw4 signaling via its inhibitory receptor KIR3DL1, but may simply reflect LD patterns between $H L A-B$ and $D R B 1$.

In the association analysis of individual amino acid residues (see below, Table 8C), the Bw4 epitope with Thr at position $80(\mathrm{Bw} 4 \mathrm{~T})$ shows a protective association $(\mathrm{OR}=0.64 ; \mathrm{p}=$ $0.0003)$ but the stronger-binding Bw4 epitope with Ile (Bw4I) does not $(\mathrm{OR}=0.92 ; \mathrm{p}=$ 0.56 ), consistent with the Bw4 association reflecting LD and not ligand mediated KIR signaling. Association analyses of the Bw4 epitope on some HLA-A molecules (ABw4) reveal no protective effect (data not shown). The frequency of $D R B 1 * 15: 01$ in Bw4+ individuals is $48 \%$ in MS patients and $16 \%$ in controls, while it is $51 \%$ in Bw4- patients and $26 \%$ in Bw4- controls, suggesting that the disease risk associated with $D R B 1 * 15: 01$ is not reduced in the Bw4 positive stratum. However, subdividing Bw4 does reveal a difference in the association pattern, and this difference cannot be attributed simply to LD. Both Bw4T 
and Bw4I are in negative LD with $D R B 1 * 15: 01\left(\mathrm{~d}^{\prime}{ }_{\mathrm{ij}}=-0.45\right.$ and -0.64 in cases, and -0.79 and -0.92 in controls, respectively) but the negative association of Bw4T with MS remains nominally significant $(\mathrm{OR}=0.071 ; \mathrm{p}=0.032)$ even in the $D R B 1 * 15: 01$ negative stratum (Table 7C).

2.5.2 HLA Ligand with KIR-Since the interaction of specific receptors and their HLA ligands is functional, we analyzed specific combinations of HLA ligands and KIR genotypes (Supplementary Table S4A). To address the issue of LD with $D R B 1 * 15: 01$, we also examined these combinations in the stratum lacking $D R B 1 * 15: 01$ (Supplementary Table S4B). The combination of Bw4 and KIR3DL 1 has been reported to be protective in the recent study of $\mathrm{MS}$ in African-Americans ${ }^{44}$ including the $D R B 1 * 15$ :01-lacking stratum. In our dataset, $\mathrm{Bw} 4$ is protective in the presence of $K I R 3 D L 1$, a gene present on virtually all KIR haplotypes $(\mathrm{OR}=0.62 ; \mathrm{p}=6.12 \mathrm{E}-04)$ but also protective in the presence of KIR2DL3 $(\mathrm{OR}=0.58 ; \mathrm{p}=9.12 \mathrm{E}-05)$. However, following stratification on $D R B 1 * 15: 01$, Bw4 and KIR3DL1 are no longer significantly protective $(\mathrm{OR}=0.75 ; \mathrm{p}=0.11)$ in the $D R B 1 * 15: 01$ negative stratum. The protective association with Bw4 and KIR2DL3, however, is still nominally significant $(\mathrm{OR}=0.62 ; \mathrm{p}=0.010)$. At the KIR genotype level, one specific combination in this $D R B 1 * 15: 01$ negative stratum (Bw4+ and KIR2DL2/ KIR2DL3) shows a nominally significant protective association $(\mathrm{OR}=0.59 ; \mathrm{p}=0.017)$, but $\mathrm{Bw} 4+$ with KIR2DL2/ KIR2DL2 (OR = 2.17; $=0.051)$, or with KIR2DL3/KIR2DL3 $(\mathrm{OR}=0.91 ; \mathrm{p}=$ $0.63)$ do not. Given the multiple comparisons in this association analysis, replication in another cohort will be critical in validating this observation.

\subsection{Association Analyses of Individual Amino Acids}

The association analyses of individual amino acids in the HLA class I and class II genes can potentially reveal functionally important aspects of disease associations. Several statistically significant associations are shown in Table 8A and dissected in Tables 8B and 8C.

Table 8B shows the individual $D R B 1$ exon 2-encoded amino acid residues associated with MS. Pro at DR $\beta$ position 11 and Arg at position 13 are significantly associated with MS (OR $=3.23 ; \mathrm{p}=2.22 \mathrm{E}-16$, each) but these specific residues are unique to $D R B 1 * 15$ and $* 16$ alleles and reflect the association of $D R B 1 * 15: 01$. The less common $D R B 1 * 15: 02$ and $D R B 1 * 16: 01$ alleles found in this population share this amino acid motif but do not confer risk to MS. Position $86 \mathrm{Val}$ is also associated with MS (OR $=2.15 ; \mathrm{p}=1.56 \mathrm{E}-14)$. Many $D R B 1$ alleles that are not associated with MS also encode Val-86 but the Val-Gly dimorphism at position 86 is the only difference between highly susceptible $D R B 1 * 15: 01$ and neutral $D R B 1 * 15: 02$. Position 86 contributes to peptide binding pocket 1, underscoring the role of position 86 dimorphism in determining peptide specificity.

Association analyses of individual HLA class I-encoded amino acid residues that constitute the KIR ligand epitopes are shown in Table 8C. As noted above, the HLA-B position 80 Bw4T subtype is protective while Bw4I, thought to be a stronger binding ligand of KIR3DL1, is not. The modest protective association of Bw4T is not due to negative $\mathrm{LD}$ with $D R B 1 * 15: 01$, as it remains nominally significant even in the $D R B 1 * 15: 01$-negative stratum (Table 7C). 
The HLA-C positions 77 and 80, which encode the $\mathrm{C} 1$ and C2 KIR ligands, are not associated with MS but, interestingly, amino acid positions 73-90, which influence the strength of KIR ligand binding ${ }^{67}$ are significantly associated. The OR for the 73-77-80-99 motif (A $\sim \mathrm{S} \sim \mathrm{N} \sim \mathrm{D})$ for the $\mathrm{C} 2$ epitope is $1.63(\mathrm{p}=2.3 \mathrm{E}-06)$. This motif, however is in $\mathrm{LD}$ with $H L A-C^{*} 07: 02$ (OR $\left.=1.9 ; \mathrm{p}=2.11 \mathrm{E}-06\right)$, the HLA-C allele in LD with DRB1*15:01. Thus, the observed association of the A S N N D C2 motif probably reflects LD rather than KIR signaling. The same motif is present in $C * 07: 01$ and $* 07: 04$, alleles not associated with MS, consistent with this interpretation.

\subsection{HLA-A*02:01 and Bw4}

The strong protective associations of $C * 03: 04 \sim B^{*} 40: 01$ and $A * 02: 01$ do not appear to reflect LD with $D R B 1 * 15: 01$ or the $\mathrm{Bw} 4$ ligand group. The $A * 02: 01$ protective association with MS has been previously reported in various populations ${ }^{14,57-61}$. In a recent study of African-American MS, the combined presence of KIR3DL1 and Bw4, its ligand, was protective, and the protective association for $\mathrm{A}^{*} 02$ was attributed to $\mathrm{LD}$ with $\mathrm{Bw} 4^{44}$. This interpretation suggests that innate immunity and NK cell function, regulated by the Bw4 ligand, account for the observed negative association with $A * 02: 01$.

Our data suggest that $A * 02: 01$ is associated with protection from MS in European Americans, and that the protection conferred by $A^{*} 02: 01$ in combination with $C^{*} 03: 04 \sim B^{*} 40: 01(\mathrm{OR}=0.15 ; \mathrm{p}=6.51 \mathrm{E}-05)$ is stronger than the observed negative association with $\mathrm{Bw} 4$ presence (OR $=0.62 ; \mathrm{p}=5.95 \mathrm{E}-04)$. In our study, $\mathrm{LD}$ is modest between $A * 02: 01$ and the Bw4 epitope (d ${ }^{\prime}{ }_{\mathrm{ij}}=0.17$ in MS patients and 0.18 in controls), but much lower than LD of $C^{*} 07: 02 \sim B^{*} 07: 02$ with $D R B 1 * 15: 01$ in MS patients (0.71) or $A * 02: 01$ with $C^{*} 03: 04 \sim B^{*} 40: 01$ in controls (0.34). The $A * 02: 01 \sim \mathrm{Bw} 4$ haplotype is as protective as Bw4 presence ( $\mathrm{OR}=0.62 ; \mathrm{p}=1.69 \mathrm{E}-03)$ (Table 9), but $A * 02: 01 \sim \mathrm{Bw} 4 \mathrm{~T}$ haplotypes are more protective ( $\mathrm{OR}=0.53 ; \mathrm{p}=7.55 \mathrm{E}-04)$, while $A * 02: 01 \sim \mathrm{Bw} 4 \mathrm{I}$ haplotypes are not, consistent with Table 8C.

LD between $A * 02: 01$ and $B w 4 T$ is comparable to that between $A * 02: 01$ and $B w 4\left(\mathrm{~d}^{\prime}{ }_{\mathrm{ij}} 0.16\right.$ in MS patients and controls), whereas LD is much stronger between $A * 02: 01$ and $C^{*}$ 05:01 $B^{*} 44: 02$ (0.59 in MS patients and 0.62 in controls). Of the $H L A-B$ alleles in protective $C \sim B$ haplotypes, $B * 40: 01$ encodes Bw6, while $B * 44: 02$ encodes Bw4T; the protection associated with $\mathrm{Bw} 4 \mathrm{~T}$ may reflect, in part, the protective $C^{*} 05: 01 \sim B^{*} 44: 02$ haplotype (and perhaps other Bw4T-encoding $H L A-B$ alleles).

\section{Discussion}

We have identified multiple $H L A$ class I and class II alleles and haplotypes associated with MS. Strong LD is a characteristic of the HLA region, and we investigated allele-pair LD and conditional asymmetric LD, and applied stratification analysis to adjust for LD in order to dissect and interpret these associations. In addition to standard case-control association analyses, we applied Hardy-Weinberg equilibrium analyses to cases and controls to validate our association findings. Many immune-related genes in the MHC were not analyzed in this study; given the LD known for the MHC, our analyses do not exclude these genes as potentially playing roles in MS susceptibility. However, association analysis, following 
stratification, proved effective at identifying the independent effects of specific HLA alleles and haplotypes. As reported in many previous studies, the DRB1*15:01 DQB1*06:02 haplotype is most strongly associated with MS risk; $D R B 1 * 03: 01 \sim D Q B 1 * 02: 01$ is also significantly associated with a recessive effect on MS risk and, as expected, is very strongly associated with MS in the $D R B 1 * 15: 01$-negative stratum. NGS HLA typing allowed the analysis of the $D R B 3$ allelic diversity on $D R B 1 * 03: 01$ haplotypes, and our analyses suggest that $D R B 3^{*} 02: 02$ may confer higher risk than $D R B 3^{*} 01: 01$, but this observation must be tested in a larger study.

$A * 02: 01, C^{*} 03: 04 \sim B^{*} 40: 01$ and the haplotype carrying all three alleles show very strong protective associations ( $\mathrm{OR}=0.15$ for the three-locus haplotype) with MS, independent of LD with $D R B 1 * 15: 01$. The protective association of the $A * 02: 01 \sim C^{*} 03: 04 \sim B^{*} 40: 01$ haplotype displays the strongest effect size of the observed $H L A$ associations in this study.

For the HLA ligands of the KIR, the presence of Bw4 was negatively associated with MS in the unstratified dataset, as noted in previous reports, but was no longer significant in the stratum lacking $D R B 1 * 15: 01$. While this observed association may simply reflect negative LD between $B W 4$ and $D R B 1^{*} 15: 01$ in this population, the two Bw4 subtypes, Bw4T and $\mathrm{Bw} 4 \mathrm{I}$, showed different association patterns. The protective association of Bw4T remained nominally significantly even in the $D R B 1 * 15$ :01-negative stratum, while $\mathrm{Bw} 4 \mathrm{I}$ was not associated in either stratum. The Bw4 motif on HLA-A molecules (all of which are Bw4I) was also not significantly protective. From the available data, we cannot distinguish between a potential effect on peptide binding mediated by this Thr/Ile polymorphism in HLA-B pocket F, differential signaling via the KIR3DL1 receptor, or a combination of the two. A recent study of HIV infection indicates that the binding of a specific HIV peptide can influence the interaction of the Bw4 epitope with the KIR3DL1 receptor ${ }^{68}$. The difference between an uncharged, polar side chain (Thr) and an aliphatic side chain (Ile) may influence peptide binding, and through differential peptide binding, KIR3DL1 signaling.

In investigating different HLA ligand/KIR genotype combinations in the $D R B 1 * 15: 01$ negative stratum, the strongest protective $\mathrm{Bw} 4$ association we observed was in combination with KIR2L2/KIR2DL3, which is stronger than Bw4 in combination with 3DL1. This protective association was nominally significant but, given the number of comparisons, validation of this observation requires testing in another large cohort. The immunological mechanism underlying the $\mathrm{Bw} 4 \mathrm{~T}$ protective association remains unclear.

Many other amino acid positions were implicated in our analyses, but, as in all HLA related association studies, they must be considered in the context of LD. Some disease associated amino acid residues simply "tag" an allele, recapitulating an already well-established allele association. These associations, the report of Raychaudhuri and colleagues notwithstanding ${ }^{69}$, do not increase our functional understanding of HLA-related disease association. However, other individual amino acid associations that do not correspond uniquely to specific alleles may provide some functional insights, although the peptide binding properties of HLA molecules are obviously determined by multiple amino acid residues. In general, the potential role of individual amino acids in disease associations can 
be best evaluated by comparing alleles that differ in disease risk, and differ in only one amino acid position.

For example, $D R B 1$ alleles encode either Gly or Val at DR $\beta$ position 86; this position contributes to peptide binding pocket $1^{70}$, which anchors the N-terminal end of the bound peptide $^{71}$. Positions 82 and 89 also contribute to pocket 1, but are invariant in this dataset and in most HLA alleles. Neither $86 \mathrm{G}$ nor $86 \mathrm{~V}$ tag a specific allele, but the predisposing $D R B 1 * 15: 01$ allele $(86 \mathrm{~V})$ and the neutral $D R B 1 * 15: 02$ allele $(86 \mathrm{G})$ differ only at encoded position 86 . In Table $8 \mathrm{~B}$, position $86 \mathrm{~V}(\mathrm{OR}=2.15 ; \mathrm{p}=1.56 \mathrm{E}-14)$ was implicated as potentially being functionally related to the observed association of $D R B 1$ with MS.

Finally, the non-Hispanic European-American cohort in this study represents a "panEuropean" population, and as such may be subject to population stratification. However, our Hardy-Weinberg analyses revealed no significant population stratification in this cohort. In addition, the frequencies of key alleles and haplotypes (e.g., $H L A-B * 18: 01$ and the $A 1 \sim B 8 \sim D R 3$ haplotype) in our cohort are consistent with those observed across Europe ${ }^{72}$, as opposed to the very high-frequencies observed for these variants in specific European populations, again suggesting that stratification in this cohort is minimal.

\subsection{Conclusions}

Some associations of specific HLA alleles, e.g., the strong protective effect of the $C^{*}$ 03:04 $B^{*} 40: 01$ haplotype, remain highly significant following stratification on $D R B 1 * 15: 01$. In general, the results of these analyses indicate that a careful consideration of LD patterns among HLA alleles is essential in the interpretation of MS association data. Overall, we conclude that specific $H L A$ class I polymorphisms are protective for MS, independent of the strong MS predisposition conferred by the $D R B 1 * 15: 01$ allele.

\section{Materials and Methods}

\subsection{Samples}

Blood samples were collected for 412 MS patients of self-identified non-Hispanic European ancestry, and 419 healthy, ethnically matched controls. MS patients were diagnosed by neurologists specialized in demyelinating diseases in accordance with well-established diagnostic and study inclusion criteria ${ }^{73}$. Controls were of self-identified non-Hispanic European ancestry and reported no history of chronic diseases for themselves or their nuclear family. De-identified genomic DNA was extracted using a standard desalting method and quantitated in duplicate using the PicoGreen dsDNA quantitation reagent. Coded DNA aliquots are stored at $-80^{\circ} \mathrm{C}$. Study protocols were approved by the UCSF Committee on Human Research and informed consent was obtained from all participants.

\subsection{Genotyping}

Locus-specific genotyping for the $14 K I R$ loci was performed as previously described ${ }^{74,75}$. Next-generation sequencing of $H L A$-class I exons 2, 3 and 4, $H L A$ class II exon 2, and $H L A$ class II exon 3 (for the $D Q B 1$ locus) on the Roche (Pleasanton, CA, USA) 454 GS FLX instrument was used to genotype $H L A-A,-C,-B, D R B 1, D R B 3 / 4 / 5, D Q A 1, D Q B 1$ and 
$D P B 1$ alleles $^{76-79}$. NGS $H L A$ sequences were assigned to $H L A$ alleles on the basis of reference sequences in IMGT/HLA Database version 3.1.0 (July 17, 2010) using Conexio (Fremantle, Australia) Assign ATF version 1.1.0.35.

$H L A$ genotyping was blinded with respect to MS patients and controls, with $15 \%$ of specimens retyped for quality assurance purposes; our NGS HLA genotypes were verified independently via HistoGenetics (Ossning, NY, USA) ${ }^{80}$ with $>98 \%$ concordance.

Discordant typings were reviewed and re-typed, and the final dataset was $100 \%$ concordant between the two NGS methods. Subject disease-status (case/control) was only released for analysis after the genotyping was completed.

\subsection{Data Analysis}

4.3.1. Tests of Association-We applied locus-level tests of heterogeneity and variantlevel chi-squared $\left(\chi^{2}\right)$ tests of association at the genotype, haplotype, locus and individual amino acid levels using BIGDAWG (v1.8.1) ${ }^{81}$. In these tests, each multi-gene group (e.g., $H L A-C \sim H L A-B)$, individual gene (e.g., $H L A-D R B I$ ) and inferred polymorphic amino acid position (e.g., DR $\beta$ position 86 ) was treated as a locus, and individual haplotypes (e.g., $H L A-C^{*} 07: 02 \sim H L A-B * 07: 02$ ), alleles (e.g., $D R B 1 * 03: 01$ ) and amino-acid residues (e.g., $\mathrm{DR} \beta$ position $86 \mathrm{~V}$ ) were treated as variants. For each comparison, variants with expected counts less than 5 in cases or controls were combined into a common "binned" category for analyses ${ }^{82}$.

We measured interaction between $K I R$ and $H L A$ loci by applying a $\chi^{2}$ test to contingency tables that crossed disease phenotype with genotype, where genotype was defined as a given KIR-HLA combination. Specifically, we tested dominant and additive effects of KIR genes and their ligands at all biallelic loci in the overall cohort in addition to sub-cohorts defined by presence of $D R B 1 * 15: 01$. From these contingency tables, we calculated odds ratio with 95\% confidence intervals, and $p$-values.

4.3.2. Test of Hardy-Weinberg Equilibrium-We performed tests for deviations from Hardy-Weinberg equilibrium (HWE) proportions using BIGDAWG and PyPop (v0.7.0) ${ }^{83}$, assessing genotyping proportions for both individual loci and specific haplotypes (using haplotypes assigned to individuals in BIGDAWG on the basis of posterior probabilities). We identified significant locus-level HWE deviations using Guo and Thompson's exact $\operatorname{method}^{84}$, and identified individual genotypes deviating significantly from HWE expectations using Chen's method ${ }^{85,86}$, using a threshold of significance of 0.05 .

4.3.3. Evaluation of Linkage Disequilibrium-We calculated normalized LD values $\left(\mathrm{d}^{\prime} \mathrm{ij}\right)^{87}$ for individual haplotypes with PyPop, and calculated conditional asymmetric LD (cALD) values, evaluating LD between sets of loci, using the "asymLD" R package (v0.1) ${ }^{88}$. Values of $\mathrm{d}^{\prime}{ }_{\mathrm{ij}}$ range from -1, when the haplotype is never observed, to 1, describing the maximum possible LD based on the frequencies of the constituent alleles. The cALD measure $W_{A / B}$ is the correlation coefficient for alleles at locus $A$ conditioned on the alleles at locus $B$, and describes the overall variation of alleles at locus $A$, given specific alleles at locus $B . W_{B / A}$ is the correlation coefficient for alleles at locus $B$, conditioned on the alleles at locus $A$, and describes the overall variation of alleles at locus $B$, given specific alleles at 
locus $A^{89}$. When there are equal numbers of alleles and complete allele correlation between both loci, the value of $W_{A / B}$ and $W_{B / A}$ is 1 , indicating no variation of alleles between loci.

4.3.4. Corrections for Multiple Comparisons-For locus-level $\chi^{2}$ tests of heterogeneity involving individual loci (i.e., $H L A-A$ and $D P B I$ ) and haplotypes of loci (e.g., $C \sim B$ and $D R B 1 \sim D Q B 1$ ), the threshold of significance was calculated as $0.05 / \mathrm{n}$, where $\mathrm{n}$ is the number of comparisons. We note that these comparisons are not necessarily independent (e.g., the $H L A-A$ locus is included in four comparisons), so that these estimates can be considered overly conservative.

Our tests of the specific hypothesis that the protective effect of $H L A-A * 02: 01$ is due to LD with the Bw4 motif ${ }^{44}$ are addressed separately from other locus-level and haplotype-level comparisons. These tests pertained to the $A \sim \mathrm{Bw} 4 / \mathrm{Bw} 6$ and $A \sim \mathrm{HLA}-\mathrm{B}$ Position 80 aminoacid variant haplotypes. Similarly, our tests of Bw4 Thr and Ile subtypes in $D R B 1 * 15: 01$ positive and -negative strata address our observation that HLA-B position $80 \mathrm{~T}$ is associated with MS, whereas position $80 \mathrm{I}$ is not, and our tests of $D R B 1$ alleles in $D R B 1 * 15: 01$-positive and -negative strata address the observation that $D Q A 1 * 01: 01$ (found on the $D R B 1 * 01: 01 \sim D Q B 1 * 05: 01$ haplotype) is protective only in the presence of $D R B 1 * 15: 01^{53}$. The threshold of significance for both of these pairs of locus-level $\chi^{2}$ tests of heterogeneity was calculated as $0.05 / 2(0.025 \mathrm{E}-2)$.

For $\chi^{2}$ tests of heterogeneity of amino-acid positions, the threshold of significance was calculated for each individual locus as $0.05 / \mathrm{n}$, where $\mathrm{n}$ is the number of variant amino-acid positions at that locus. Results are not presented for positions that did not display significant position-level heterogeneity.

In cases where locus-level tests of heterogeneity were not significant (p-value $>$ the threshold of significance), the threshold of significance for the $\chi^{2}$ tests of association was calculated as $0.05 / \mathrm{n}$, where $\mathrm{n}$ equals the number of variants at that locus.

4.3.5. Statistical Power Analysis-We used the pwr.chisq.test function in the R "pwr" package (version 1.2-0) to evaluate the size of an effect detectable in our dataset with the recommended statistical power $(1-\beta)$ of 0.8 with an a of $0.05^{90}$. For association tests of alleles and haplotypes, with 31 allele categories, we expect to detect small effect sizes (0.121). For tests of locus presence, motifs and amino acid positions, with 2-5 categories, we expect to detect very small effect sizes $(0.068-0.085)$.

\subsection{Data Access}

The HLA and KIR genotype data used for the analyses described here have been deposited into ImmPort (http://www.immport.org), the public data-sharing resource of the National Institute of Allergy and Infectious Disease's (NIAID) Division of Allergy, Immunology, and Transplantation (DAIT) and Division of Microbiology and Infectious Diseases (DMID), and can be accessed under the ImmPort Study Accession Number SDY1045 (doi:10.21430/ M3QW34U2SG). 


\subsection{Code Availability}

The source code for BIGDAWG is available online at https://cran.r-project.org/web/ packages/BIGDAWG/index.html and https://github.com/IgDAWG/BIGDAWG, with version 1.8.1 code at https://github.com/IgDAWG/BIGDAWG/tree/ eb0b4140ec3fb85b1a4fba5826ffc9f9e3239d10.

The source code for asymLD v0.1 is available online at https://cran.r-project.org/web/ packages/asymLD/index.html.

The source code for PyPop is available online at https://github.com/alexlancaster/pypop, with version 0.70 code at https://github.com/alexlancaster/pypop/tree/ 3f29d4b53548ce4deb60a5960368627999396653.

\section{Supplementary Material}

Refer to Web version on PubMed Central for supplementary material.

\section{Acknowledgments}

This work was supported National Institutes of Health (NIH) National Institute of Allergy and Infectious Disease (NIAID) grants U01AI067068 (Supplement) "The Role of KIR and HLA in Multiple Sclerosis" (ET) and R01AI28775 (SM), National Institute of General Medical Sciences (NIGMS) grant R01GM109030 (SM) and National Institute of Neurological Disorders and Stroke (NINDS) grant R01NS026799 (JRO). The content is solely the responsibility of the authors and does not necessarily reflect the official views of the NIAID, NIGMS, NINDS NIH or United States Government. We thank President Barack H. Obama for his support and appreciation of American science and basic research.

\section{Literature Cited}

1. Sawcer S, Franklin RJ, Ban M. Multiple sclerosis genetics. Lancet Neurol. 2014; 13(7):700-9. [PubMed: 24852507]

2. Bertrams J, Kuwert E, Liedtke U. HL-A antigens and multiple sclerosis. Tissue Antigens. 1972; 2(5):405-8. [PubMed: 4655776]

3. Naito S, Namerow N, Mickey MR, Terasaki PI. Multiple sclerosis: association with HL-A3. Tissue Antigens. 1972; 2(1):1-4. [PubMed: 5077731]

4. Barcellos LF, Oksenberg JR, Green AJ, Bucher P, Rimmler JB, Schmidt S, et al. Genetic basis for clinical expression in multiple sclerosis. Brain. 2002; 125(Pt 1):150-8. [PubMed: 11834600]

5. Marrosu MG, Murru MR, Costa G, Cucca F, Sotgiu S, Rosati G, et al. Multiple sclerosis in Sardinia is associated and in linkage disequilibrium with HLA-DR3 and -DR4 alleles. Am J Hum Genet. 1997; 61(2):454-7. [PubMed: 9311753]

6. Modin H, Olsson W, Hillert J, Masterman T. Modes of action of HLA-DR susceptibility specificities in multiple sclerosis. Am J Hum Genet. 2004; 74(6):1321-2. [PubMed: 15195659]

7. Marrosu MG, Muntoni F, Murru MR, Spinicci G, Pischedda MP, Goddi F, et al. Sardinian multiple sclerosis is associated with HLA-DR4: a serologic and molecular analysis. Neurology. 1988; 38(11):1749-53. [PubMed: 2903464]

8. Yoshimura S, Isobe N, Yonekawa T, Matsushita T, Masaki K, Sato S, et al. Genetic and infectious profiles of Japanese multiple sclerosis patients. PLoS One. 2012; 7(11):e48592. [PubMed: 23152786]

9. Brassat D, Salemi G, Barcellos LF, McNeill G, Proia P, Hauser SL, et al. The HLA locus and multiple sclerosis in Sicily. Neurology. 2005; 64(2):361-3. [PubMed: 15668443] 
10. Matsuoka T, Matsushita T, Osoegawa M, Kawano Y, Minohara M, Mihara F, et al. Association of the HLA-DRB1 alleles with characteristic MRI features of Asian multiple sclerosis. Mult Scler. 2008; 14(9):1181-90. [PubMed: 18952831]

11. Kwon OJ, Karni A, Israel S, Brautbar C, Amar A, Meiner Z, et al. HLA class II susceptibility to multiple sclerosis among Ashkenazi and non-Ashkenazi Jews. Arch Neurol. 1999; 56(5):555-60. [PubMed: 10328250]

12. International Multiple Sclerosis Genetics C, Wellcome Trust Case Control C. Sawcer S, Hellenthal G, Pirinen M, Spencer CC, et al. Genetic risk and a primary role for cell-mediated immune mechanisms in multiple sclerosis. Nature. 2011; 476(7359):214-9. [PubMed: 21833088]

13. Cocco E, Sardu C, Pieroni E, Valentini M, Murru R, Costa G, et al. HLA-DRB1-DQB1 haplotypes confer susceptibility and resistance to multiple sclerosis in Sardinia. PLoS One. 2012; 7(4):e33972. [PubMed: 22509268]

14. Patsopoulos NA, Barcellos LF, Hintzen RQ, Schaefer C, van Duijn CM, Noble JA, et al. Finemapping the genetic association of the major histocompatibility complex in multiple sclerosis: HLA and non-HLA effects. PLoS Genet. 2013; 9(11):e1003926. [PubMed: 24278027]

15. Isobe N, Gourraud PA, Harbo HF, Caillier SJ, Santaniello A, Khankhanian P, et al. Genetic risk variants in African Americans with multiple sclerosis. Neurology. 2013; 81(3):219-27. [PubMed: 23771490]

16. Karni A, Kohn Y, Safirman C, Abramsky O, Barcellos L, Oksenberg JR, et al. Evidence for the genetic role of human leukocyte antigens in low frequency DRB1*1501 multiple sclerosis patients in Israel. Mult Scler. 1999; 5(6):410-5. [PubMed: 10618697]

17. Campbell RD, Trowsdale J. Map of the human MHC. Immunology today. 1993; 14(7):349-52. [PubMed: 8363724]

18. Andersson G. Evolution of the human HLA-DR region. Front Biosci. 1998; 27(3):d739-45.

19. Erlich HA, Valdes AM, McDevitt SL, Simen BB, Blake LA, McGowan KR, et al. Next generation sequencing reveals the association of DRB3*02:02 with type 1 diabetes. Diabetes. 2013; 62(7): 2618-22. [PubMed: 23462545]

20. Zhao LP, Alshiekh S, Zhao M, Carlsson A, Larsson HE, Forsander G, et al. Next-Generation Sequencing Reveals That HLA-DRB3, -DRB4, and -DRB5 May Be Associated With Islet Autoantibodies and Risk for Childhood Type 1 Diabetes. Diabetes. 2016; 65(3):710-8. [PubMed: 26740600]

21. Le WB, Shi JS, Zhang T, Liu L, Qin HZ, Liang S, et al. HLA-DRB1*15:01 and HLADRB3*02:02 in PLA2R-Related Membranous Nephropathy. J Am Soc Nephrol. 2017; 28(5): 1642-1650. [PubMed: 28028136]

22. Mayo L, Quintana FJ, Weiner HL. The innate immune system in demyelinating disease. Immunological reviews. 2012; 248(1):170-87. [PubMed: 22725961]

23. Gross CC, Schulte-Mecklenbeck A, Runzi A, Kuhlmann T, Posevitz-Fejfar A, Schwab N, et al. Impaired NK-mediated regulation of T-cell activity in multiple sclerosis is reconstituted by IL-2 receptor modulation. Proceedings of the National Academy of Sciences of the United States of America. 2016; 113(21):E2973-82. [PubMed: 27162345]

24. Backstrom E, Chambers BJ, Ho EL, Naidenko OV, Mariotti R, Fremont DH, et al. Natural killer cell-mediated lysis of dorsal root ganglia neurons via RAE1/NKG2D interactions. European journal of immunology. 2003; 33(1):92-100. [PubMed: 12594837]

25. Backstrom E, Chambers BJ, Kristensson K, Ljunggren HG. Direct NK cell-mediated lysis of syngenic dorsal root ganglia neurons in vitro. Journal of immunology (Baltimore, Md : 1950). 2000; 165(9):4895-900.

26. Shi FD, Takeda K, Akira S, Sarvetnick N, Ljunggren HG. IL-18 directs autoreactive T cells and promotes autodestruction in the central nervous system via induction of IFN-gamma by NK cells. Journal of immunology (Baltimore, Md : 1950). 2000; 165(6):3099-104.

27. Vollmer TL, Liu R, Price M, Rhodes S, La Cava A, Shi FD. Differential effects of IL-21 during initiation and progression of autoimmunity against neuroantigen. Journal of immunology (Baltimore, Md : 1950). 2005; 174(5):2696-701.

28. Colonna M, Borsellino G, Falco M, Ferrara GB, Strominger JL. HLA-C is the inhibitory ligand that determines dominant resistance to lysis by NK1- and NK2-specific natural killer cells. 
Proceedings of the National Academy of Sciences of the United States of America. 1993; 90(24): 12000-4. [PubMed: 8265660]

29. Winter CC, Gumperz JE, Parham P, Long EO, Wagtmann N. Direct binding and functional transfer of NK cell inhibitory receptors reveal novel patterns of HLA-C allotype recognition. J Immunol. 1998; 161(2):571-7. [PubMed: 9670929]

30. Carena I, Shamshiev A, Donda A, Colonna M, Libero GD. Major histocompatibility complex class I molecules modulate activation threshold and early signaling of T cell antigen receptor-gamma/ delta stimulated by nonpeptidic ligands. The Journal of experimental medicine. 1997; 186(10): 1769-74. [PubMed: 9362537]

31. Cella M, Longo A, Ferrara GB, Strominger JL, Colonna M. NK3-specific natural killer cells are selectively inhibited by Bw4-positive HLA alleles with isoleucine 80. J Exp Med. 1994; 180(4): 1235-42. [PubMed: 7931060]

32. Carr WH, Pando MJ, Parham P. KIR3DL1 polymorphisms that affect NK cell inhibition by HLABw4 ligand. J Immunol. 2005; 175(8):5222-9. [PubMed: 16210627]

33. Hansasuta P, Dong T, Thananchai H, Weekes M, Willberg C, Aldemir H, et al. Recognition of HLA-A3 and HLA-A11 by KIR3DL2 is peptide-specific. European journal of immunology. 2004; 34(6):1673-9. [PubMed: 15162437]

34. Morvan M, David G, Sebille V, Perrin A, Gagne K, Willem C, et al. Autologous and allogeneic HLA KIR ligand environments and activating KIR control KIR NK-cell functions. European journal of immunology. 2008; 38(12):3474-86. [PubMed: 19016529]

35. Fauriat C, Ivarsson MA, Ljunggren HG, Malmberg KJ, Michaelsson J. Education of human natural killer cells by activating killer cell immunoglobulin-like receptors. Blood. 2010; 115(6):1166-74. [PubMed: 19903900]

36. Bottino C, Castriconi R, Moretta L, Moretta A. Cellular ligands of activating NK receptors. Trends Immunol. 2005; 26(4):221-6. [PubMed: 15797513]

37. Graef T, Moesta AK, Norman PJ, Abi-Rached L, Vago L, Older Aguilar AM, et al. KIR2DS4 is a product of gene conversion with KIR3DL2 that introduced specificity for HLA-A*11 while diminishing avidity for HLA-C. J Exp Med. 2009; 206(11):2557-72. [PubMed: 19858347]

38. Lorentzen AR, Karlesen TH, Olsson M, Smestad C, Mero I-L, Woldseth B, et al. Killer immunoglobulin-lik receptor ligand HLA-Bw4 protects against multiple sclerosis. Ann Neurol. 2009; 65(6):658-66. [PubMed: 19630074]

39. Fusco C, Guerini FR, Nocera G, Ventrella G, Caputo D, Valentino MA, et al. KIRs and their HLA ligands in remitting-relapsing multiple sclerosis. Journal of neuroimmunology. 2010; 229(1-2): 232-7. [PubMed: 20826009]

40. Garcia-Leon JA, Pinto-Medel MJ, Garcia-Trujillo L, Lopez-Gomez C, Oliver-Martos B, PratArrojo I, et al. Killer cell immunoglobulin-like receptor genes in Spanish multiple sclerosis patients. Molecular immunology. 2011; 48(15-16):1896-902. [PubMed: 21665278]

41. Jelcic I, Hsu KC, Kakalacheva K, Breiden P, Dupont B, Uhrberg M, et al. Killer immunoglobulinlike receptor locus polymorphisms in multiple sclerosis. Multiple sclerosis (Houndmills, Basingstoke, England). 2012; 18(7):951-8.

42. Gustavsen MW, Viken MK, Celius EG, Berge T, Mero IL, Berg-Hansen P, et al. Oligoclonal band phenotypes in MS differ in their HLA class II association, while specific KIR ligands at HLA class I show association to MS in general. Journal of neuroimmunology. 2014; 274(1-2):174-9. [PubMed: 25037176]

43. Bettencourt A, Silva AM, Carvalho C, Leal B, Santos E, Costa PP, et al. The role of KIR2DS1 in multiple sclerosis-KIR in Portuguese MS patients. Journal of neuroimmunology. 2014; 269(1-2): 52-5. [PubMed: 24529855]

44. Hollenbach JA, Pando MJ, Caillier SJ, Gourraud PA, Oksenberg JR. The killer immunoglobulinlike receptor KIR3DL1 in combination with HLA-Bw4 is protective against multiple sclerosis in African Americans. Genes Immun. 2016; 17(3):199-202. [PubMed: 26866467]

45. Olerup O, Hillert J. HLA class II-associated genetic susceptibility in multiple sclerosis: a critical evaluation. Tissue Antigens. 1991; 38(1):1-15. [PubMed: 1926129]

46. Schmidt H, Williamson D, Ashley-Koch A. HLA-DR15 haplotype and multiple sclerosis: a HuGE review. Am J Epidemiol. 2007; 165(10):1097-109. [PubMed: 17329717] 
47. Oksenberg JR, Barcellos LF, Cree BA, Baranzini SE, Bugawan TL, Khan O, et al. Mapping multiple sclerosis susceptibility to the HLA-DR locus in African Americans. Am J Hum Genet. 2004; 74(1):160-7. [PubMed: 14669136]

48. Lampis R, Morelli L, Congia M, Macis MD, Mulargia A, Loddo M, et al. The inter-regional distribution of HLA class II haplotypes indicates the suitability of the Sardinian population for case-control association studies in complex diseases. Hum Mol Genet. 2000; 9(20):2959-65. [PubMed: 11115839]

49. Agrawal S, Srivastava SK, Borkar M, Chaudhuri TK. Genetic affinities of north and northeastern populations of India: inference from HLA-based study. Tissue Antigens. 2008; 72(2):120-30. [PubMed: 18721272]

50. Papassavas EC, Spyropoulou-Vlachou M, Papassavas AC, Schipper RF, Doxiadis IN, Stavropoulos-Giokas C. MHC class I and class II phenotype, gene, and haplotype frequencies in Greeks using molecular typing data. Hum Immunol. 2000; 61(6):615-23. [PubMed: 10825590]

51. Doherty DG, Vaughan RW, Donaldson PT, Mowat AP. HLA DQA, DQB, and DRB genotyping by oligonucleotide analysis: distribution of alleles and haplotypes in British caucasoids. Hum Immunol. 1992; 34(1):53-63. [PubMed: 1399722]

52. Uinuk-Ool TS, Takezaki N, Derbeneva OA, Volodko NV, Sukernik RI. Variation of HLA class II genes in the Nganasan and Ket, two aboriginal Siberian populations. European journal of immunogenetics : official journal of the British Society for Histocompatibility and Immunogenetics. 2004; 31(1):43-51. [PubMed: 15009181]

53. Moutsianas L, Jostins L, Beecham AH, Dilthey AT, Xifara DK, Ban M, et al. Class II HLA interactions modulate genetic risk for multiple sclerosis. Nat Genet. 2015; 47(10):1107-13. [PubMed: 26343388]

54. Barcellos LF, Sawcer S, Ramsay PP, Baranzini SE, Thomson G, Briggs F, et al. Heterogeneity at the HLA-DRB1 locus and risk for multiple sclerosis. Hum Mol Genet. 2006; 15(18):2813-24. [PubMed: 16905561]

55. Dyment DA, Herrera BM, Cader MZ, Willer CJ, Lincoln MR, Sadovnick AD, et al. Complex interactions among MHC haplotypes in multiple sclerosis: susceptibility and resistance. Hum Mol Genet. 2005; 14(14):2019-26. [PubMed: 15930013]

56. Ramagopalan SV, Anderson C, Sadovnick AD, Ebers GC. Genomewide study of multiple sclerosis. N Engl J Med. 2007; 357(21):2199-200. [PubMed: 18032773]

57. Fogdell-Hahn A, Ligers A, Gronning M, Hillert J, Olerup O. Multiple sclerosis: a modifying influence of HLA class I genes in an HLA class II associated autoimmune disease. Tissue Antigens. 2000; 55(2):140-8. [PubMed: 10746785]

58. Harbo HF, Lie BA, Sawcer S, Celius EG, Dai KZ, Oturai A, et al. Genes in the HLA class I region may contribute to the HLA class II-associated genetic susceptibility to multiple sclerosis. Tissue Antigens. 2004; 63(3):237-47. [PubMed: 14989713]

59. Brynedal B, Duvefelt K, Jonasdottir G, Roos IM, Akesson E, Palmgren J, et al. HLA-A confers an HLA-DRB1 independent influence on the risk of multiple sclerosis. PLoS One. 2007; 2(7):e664. [PubMed: 17653284]

60. Bergamaschi L, Leone MA, Fasano ME, Guerini FR, Ferrante D, Bolognesi E, et al. HLA-class I markers and multiple sclerosis susceptibility in the Italian population. Genes Immun. 2010; 11(2): 173-80. [PubMed: 19907433]

61. Sawcer S, Hellenthal G, Pirinen M, Spencer CC, Patsopoulos NA, Moutsianas L, et al. Genetic risk and a primary role for cell-mediated immune mechanisms in multiple sclerosis. Nature. 2011; 476(7359):214-9. [PubMed: 21833088]

62. Goris A, van Setten J, Diekstra F, Ripke S, Patsopoulos NA, Sawcer SJ, et al. No evidence for shared genetic basis of common variants in multiple sclerosis and amyotrophic lateral sclerosis. Hum Mol Genet. 2014; 23(7):1916-22. [PubMed: 24234648]

63. Yeo TW, De Jager PL, Gregory SG, Barcellos LF, Walton A, Goris A, et al. A second major histocompatibility complex susceptibility locus for multiple sclerosis. Ann Neurol. 2007; 61(3): 228-36. [PubMed: 17252545]

64. Rioux JD, Goyette P, Vyse TJ, Hammarstrom L, Fernando MM, Green T, et al. Mapping of multiple susceptibility variants within the MHC region for 7 immune-mediated diseases. 
Proceedings of the National Academy of Sciences of the United States of America. 2009; 106(44): 18680-5. [PubMed: 19846760]

65. Mack SJ, Tu B, Lazaro A, Yang R, Lancaster AK, Cao K, et al. HLA-A, -B, -C, and -DRB1 allele and haplotype frequencies distinguish Eastern European Americans from the general European American population. Tissue Antigens. 2009; 73(1):17-32. [PubMed: 19000140]

66. Mack SJ, Tu B, Yang R, Masaberg C, Ng J, Hurley CK. Human leukocyte antigen-A, -B, -C, DRB1 allele and haplotype frequencies in Americans originating from southern Europe: contrasting patterns of population differentiation between Italian and Spanish Americans. Human immunology. 2011; 72(2):144-9. [PubMed: 20974205]

67. Mandelboim O, Reyburn HT, Sheu EG, Vales-Gomez M, Davis DM, Pazmany L, et al. The binding site of NK receptors on HLA-C molecules. Immunity. 1997; 6(3):341-50. [PubMed: 9075934]

68. Fadda L, O'Connor GM, Kumar S, Piechocka-Trocha A, Gardiner CM, Carrington M, et al. Common HIV-1 peptide variants mediate differential binding of KIR3DL1 to HLA-Bw4 molecules. Journal of virology. 2011; 85(12):5970-4. [PubMed: 21471246]

69. Raychaudhuri S, Sandor C, Stahl EA, Freudenberg J, Lee HS, Jia X, et al. Five amino acids in three HLA proteins explain most of the association between MHC and seropositive rheumatoid arthritis. Nat Genet. 2012; 44(3):291-6. [PubMed: 22286218]

70. Natarajan K, Li H, Mariuzza RA, Margulies DH. MHC class I molecules, structure and function. Reviews in immunogenetics. 1999; 1(1):32-46. [PubMed: 11256571]

71. Smith KJ, Pyrdol J, Gauthier L, Wiley DC, Wucherpfennig KW. Crystal structure of HLA-DR2 (DRA*0101, DRB1*1501) complexed with a peptide from human myelin basic protein. The Journal of experimental medicine. 1998; 188(8):1511-20. [PubMed: 9782128]

72. Dos Santos EJ, McCabe A, Gonzalez-Galarza FF, Jones AR, Middleton D. Allele Frequencies Net Database: Improvements for storage of individual genotypes and analysis of existing data. Human immunology. 2016; 77(3):238-48. [PubMed: 26585775]

73. Polman CH, Reingold SC, Edan G, Filippi M, Hartung HP, Kappos L, et al. Diagnostic criteria for multiple sclerosis: 2005 revisions to the "McDonald Criteria". Ann Neurol. 2005; 58(6):840-6. [PubMed: 16283615]

74. Houtchens KA, Nichols RJ, Ladner MB, Boal HE, Sollars C, Geraghty DE, et al. High-throughput killer cell immunoglobulin-like receptor genotyping by MALDI-TOF mass spectrometry with discovery of novel alleles. Immunogenetics. 2007; 59(7):525-537. [PubMed: 17464504]

75. Hollenbach JALM, Saeteurn K, Taylor KD, Mei L, Haritunians T, McGovern DP, Erlich HA, Rotter JI, Trachtenberg EA. Susceptibility to Crohn's disease is mediated by KIR2DL2/KIR2DL3 heterozygosity and the HLA-C ligand. Immunogenetics. 2009; 61:663-671. [PubMed: 19789864]

76. Bentley G, Higuchi R, Hoglund B, Goodridge D, Sayer D, Trachtenberg EA, et al. High-resolution, high-throughput HLA genotyping by next-generation sequencing. Tissue antigens. 2009; 74(5): 393-403. [PubMed: 19845894]

77. Trachtenberg, E, Holcomb, CL. Transplantation Immunology: Methods and Protocols, Second Edition, Methods in Molecular Biology. Vol. 1034. Springer Science+Business Media, LLC; 2013. Next-Generation HLA Sequencing Using the 454 GS FLX System. 2013

78. Moonsamy PV, Williams T, Bonella P, Holcomb CL, Hoglund BN, Hillman G, et al. High throughput HLA genotyping using 454 sequencing and the Fluidigm Access Array System for simplified amplicon library preparation. Tissue antigens. 2013; 81(3):141-9. [PubMed: 23398507]

79. Holcomb CL, Hoglund B, Anderson MW, Blake LA, Bohme I, Egholm M, et al. A multi-site study using high-resolution HLA genotyping by next generation sequencing. Tissue antigens. 2011; 77(3):206-17. [PubMed: 21299525]

80. Cereb N, Kim HR, Ryu J, Yang SY. Advances in DNA sequencing technologies for high resolution HLA typing. Hum Immunol. 2015; 76(12):923-7. [PubMed: 26423536]

81. Pappas DJ, Marin W, Hollenbach JA, Mack SJ. Bridging ImmunoGenomic Data Analysis Workflow Gaps (BIGDAWG): An integrated case-control analysis pipeline. Hum Immunol. 2016; 77(3):283-7. [PubMed: 26708359] 
82. Hollenbach JA, Mack SJ, Thomson G, Gourraud PA. Analytical methods for disease association studies with immunogenetic data. Methods in molecular biology (Clifton, N.J.). 2012; 882:24566.

83. Lancaster AK, Single RM, Solberg OD, Nelson MP, Thomson G. PyPop update-a software pipeline for large-scale multilocus population genomics. Tissue Antigens. 2007; 69(Suppl 1):1927. [PubMed: 17445199]

84. Guo SW, Thompson EA. Performing the exact test of Hardy-Weinberg proportion for multiple alleles. Biometrics. 1992; 48(2):361-72. [PubMed: 1637966]

85. Chen JJ, Thomson G. The variance for the disequilibrium coefficient in the individual HardyWeinberg test. Biometrics. 1999; 55(4):1269-72. [PubMed: 11315081]

86. Chen JJ, Hollenbach JA, Trachtenberg EA, Just JJ, Carrington M, Ronningen KS, et al. HardyWeinberg testing for HLA class II (DRB1, DQA1, DQB1, and DPB1) loci in 26 human ethnic groups. Tissue Antigens. 1999; 54(6):533-42. [PubMed: 10674966]

87. Lewontin RC. The Interaction of Selection and Linkage. I. General Considerations; Heterotic Models. Genetics. 1964; 49(1):49-67. [PubMed: 17248194]

88. Single RM, Strayer N, Thomson G, Paunic V, Albrecht M, Maiers M. Asymmetric linkage disequilibrium: Tools for assessing multiallelic LD. Hum Immunol. 2016; 77(3):288-94. [PubMed: 26359129]

89. Thomson G, Single RM. Conditional asymmetric linkage disequilibrium (ALD): extending the biallelic r2 measure. Genetics. 2014; 198(1):321-31. [PubMed: 25023400]

90. Cohen, J. Statistical power analysis for the behavioral sciences. Lawrence Earlbaum Associates; Hillsdale, NJ: 1988. 20-26. 


\section{Table 1}

Locus-level Heterogeneity between Multiple Sclerosis Patients and Controls

\begin{tabular}{|c|c|c|c|c|}
\hline Locus & $\chi^{\mathbf{2}}$ & d.f. & p-value & Significance \\
\hline A & 43.3012 & 17 & $4.34 \mathrm{E}-04$ & $*$ \\
\hline A $\sim$ DRB1 & 169.5478 & 38 & $<2.22 \mathrm{E}-16$ & $*$ \\
\hline A $\sim$ DRB1 DQB1 & 161.7085 & 39 & $<2.22 \mathrm{E}-16$ & $*$ \\
\hline A C $\sim$ B DRB1 DQB 1 DPB1 & 42.5118 & 11 & $1.3205 \mathrm{E}-05$ & $*$ \\
\hline C B & 81.8819 & 33 & $4.9007 \mathrm{E}-06$ & $*$ \\
\hline C B DRB1 & 100.52 & 24 & $2.45 \mathrm{E}-11$ & $*$ \\
\hline DRB1 $\sim \mathrm{DQB} 1$ & 159.1034 & 26 & $<2.22 \mathrm{E}-16$ & $*$ \\
\hline DPB1 & 21.061 & 15 & $1.35 \mathrm{E}-01$ & NS \\
\hline
\end{tabular}

$\chi^{2}$ : Chi-squared value.

d.f.: Degrees of freedom.

${ }^{1}$ After correcting for eight comparisons, significance was evaluated at the $6.25 \mathrm{E}-03$ level. Significant p-values are indicated with asterisks. NS: Not Significant. 


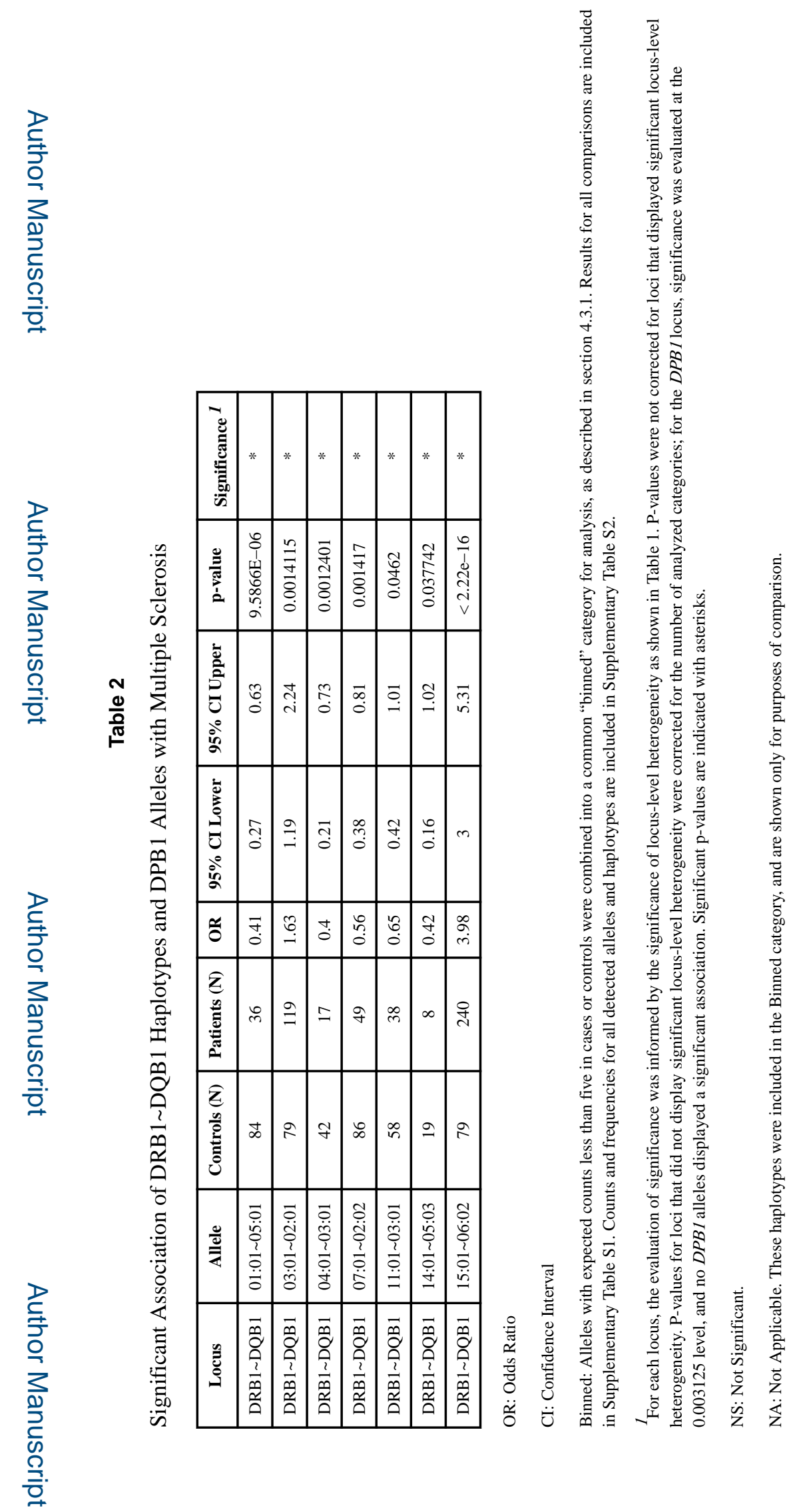

Genes Immun. Author manuscript; available in PMC 2019 April 18. 


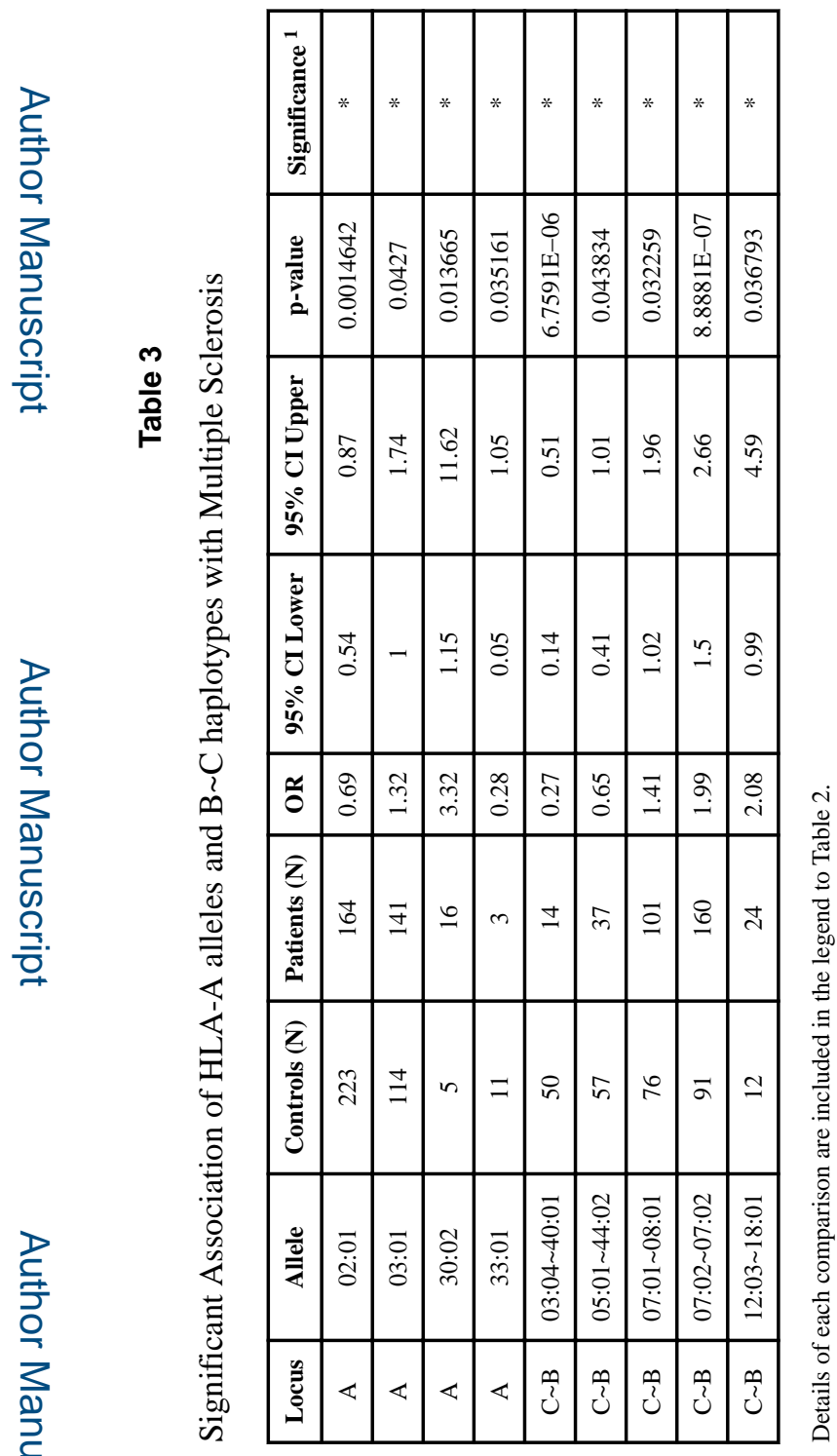



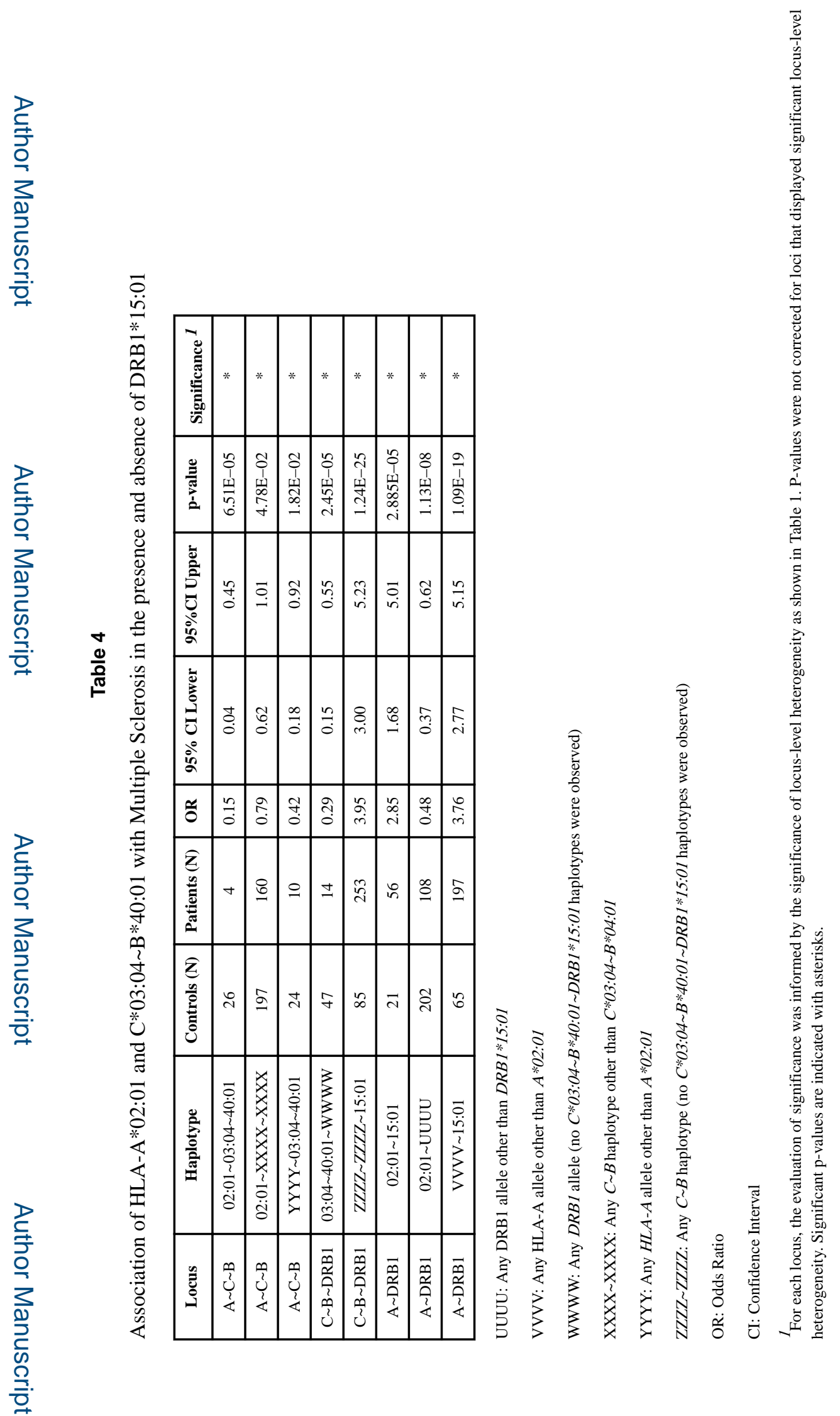

Genes Immun. Author manuscript; available in PMC 2019 April 18. 

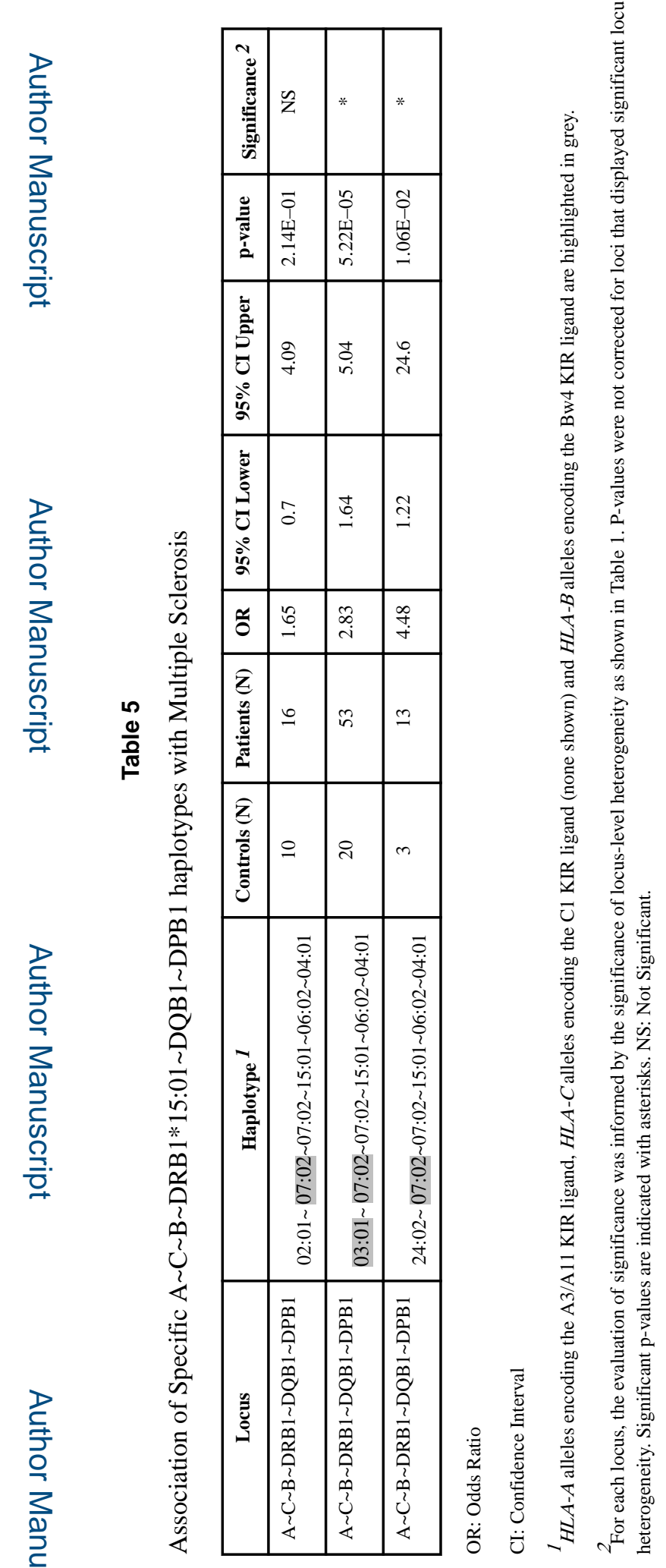

Genes Immun. Author manuscript; available in PMC 2019 April 18. 


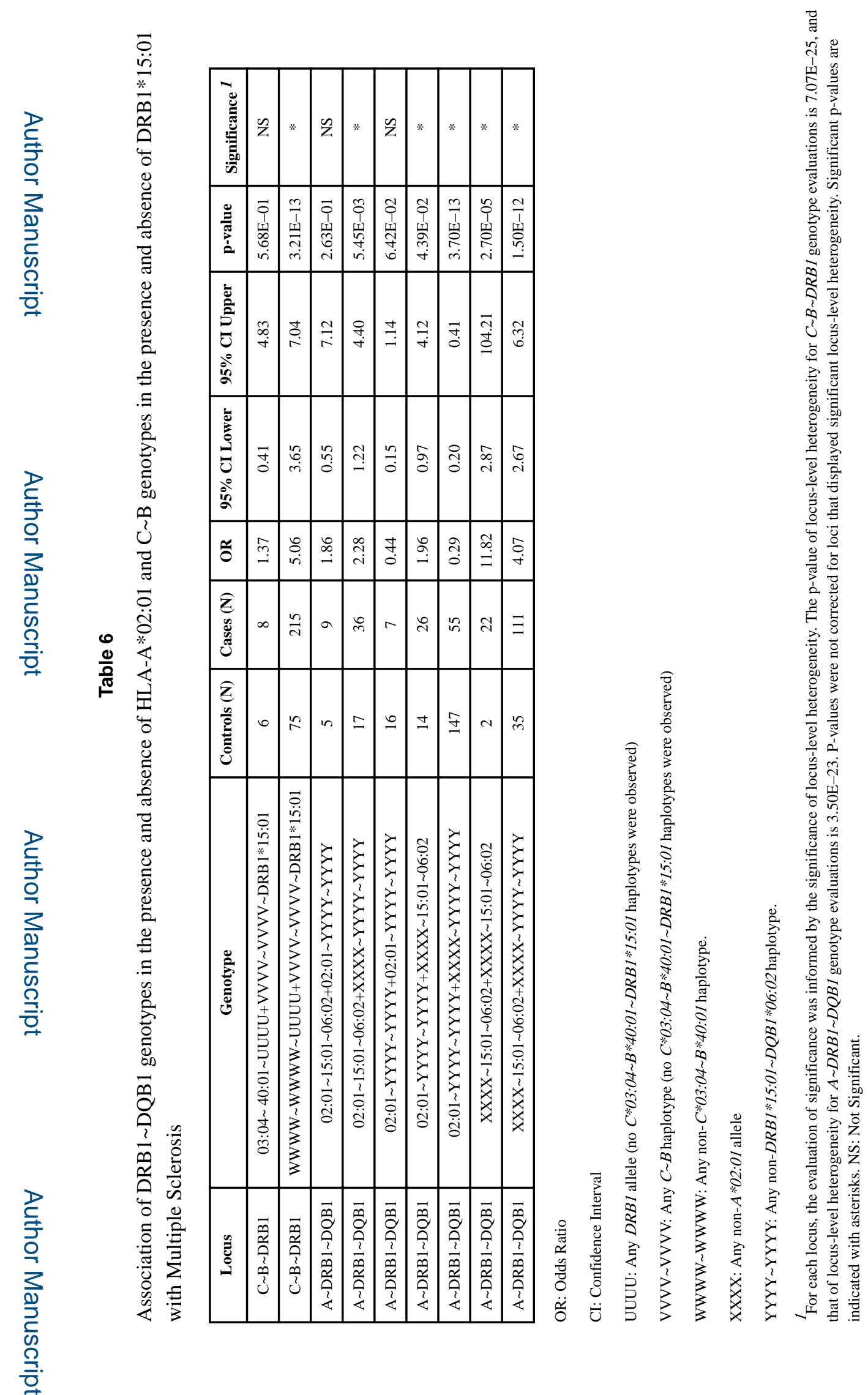

Genes Immun. Author manuscript; available in PMC 2019 April 18. 


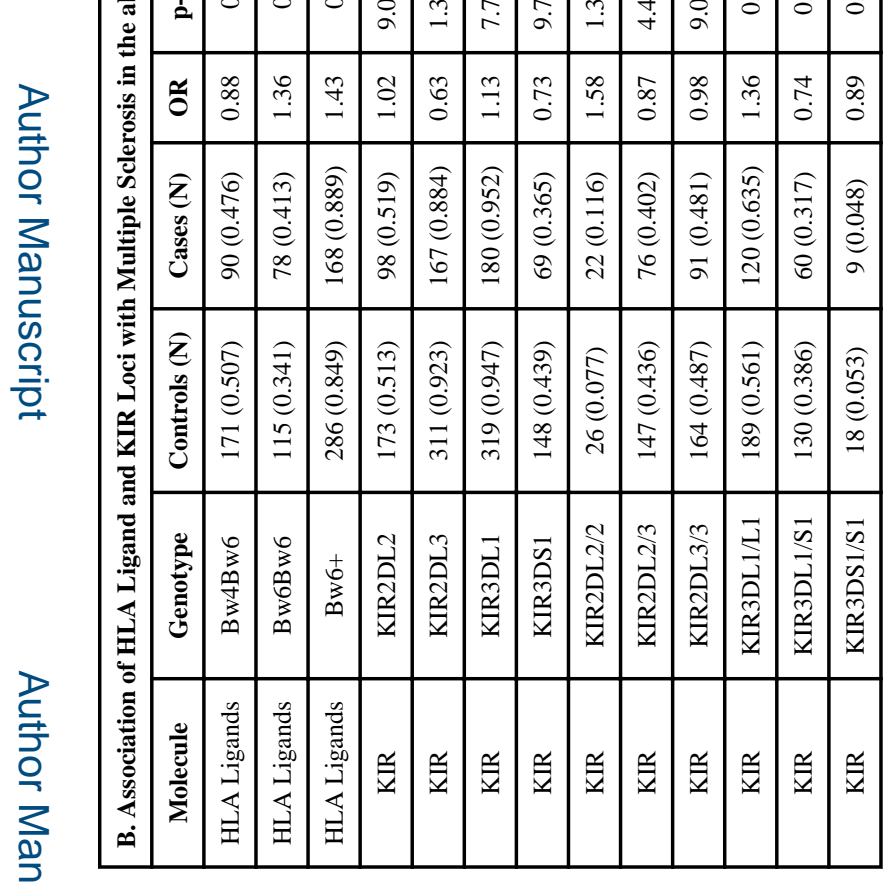




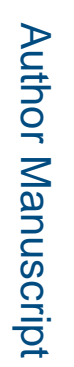

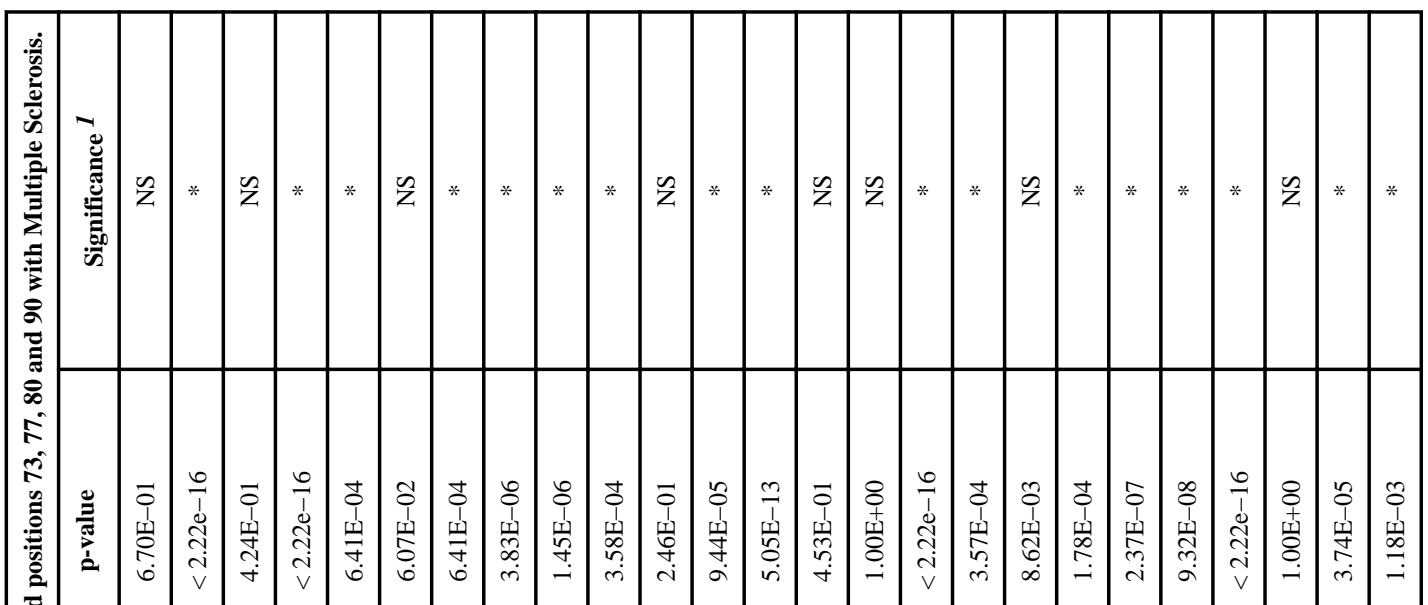

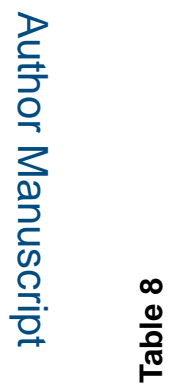

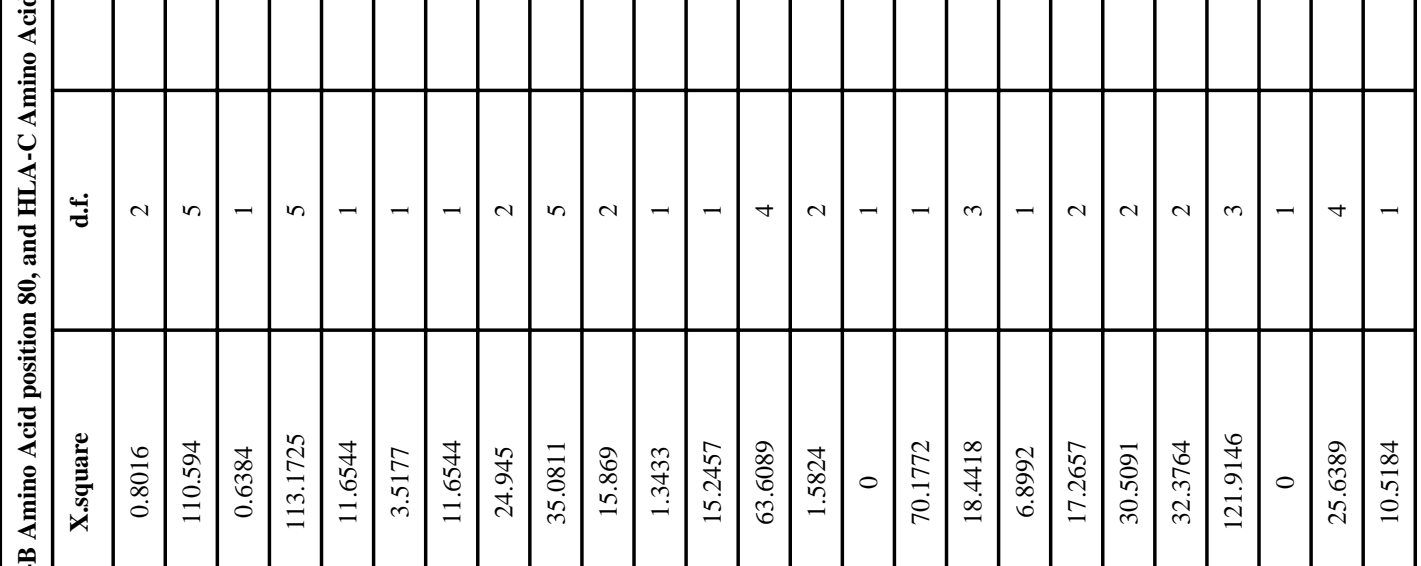

I 


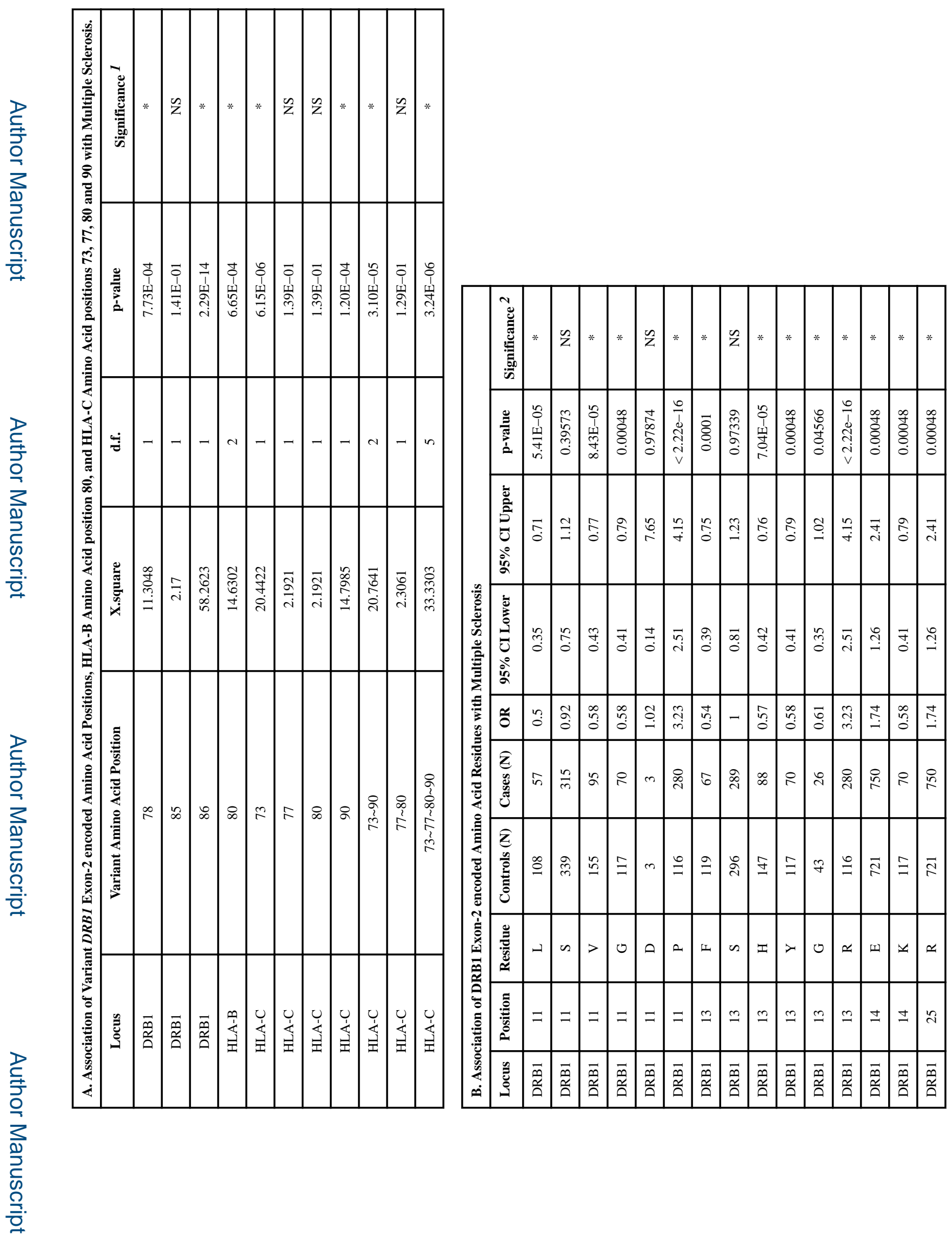




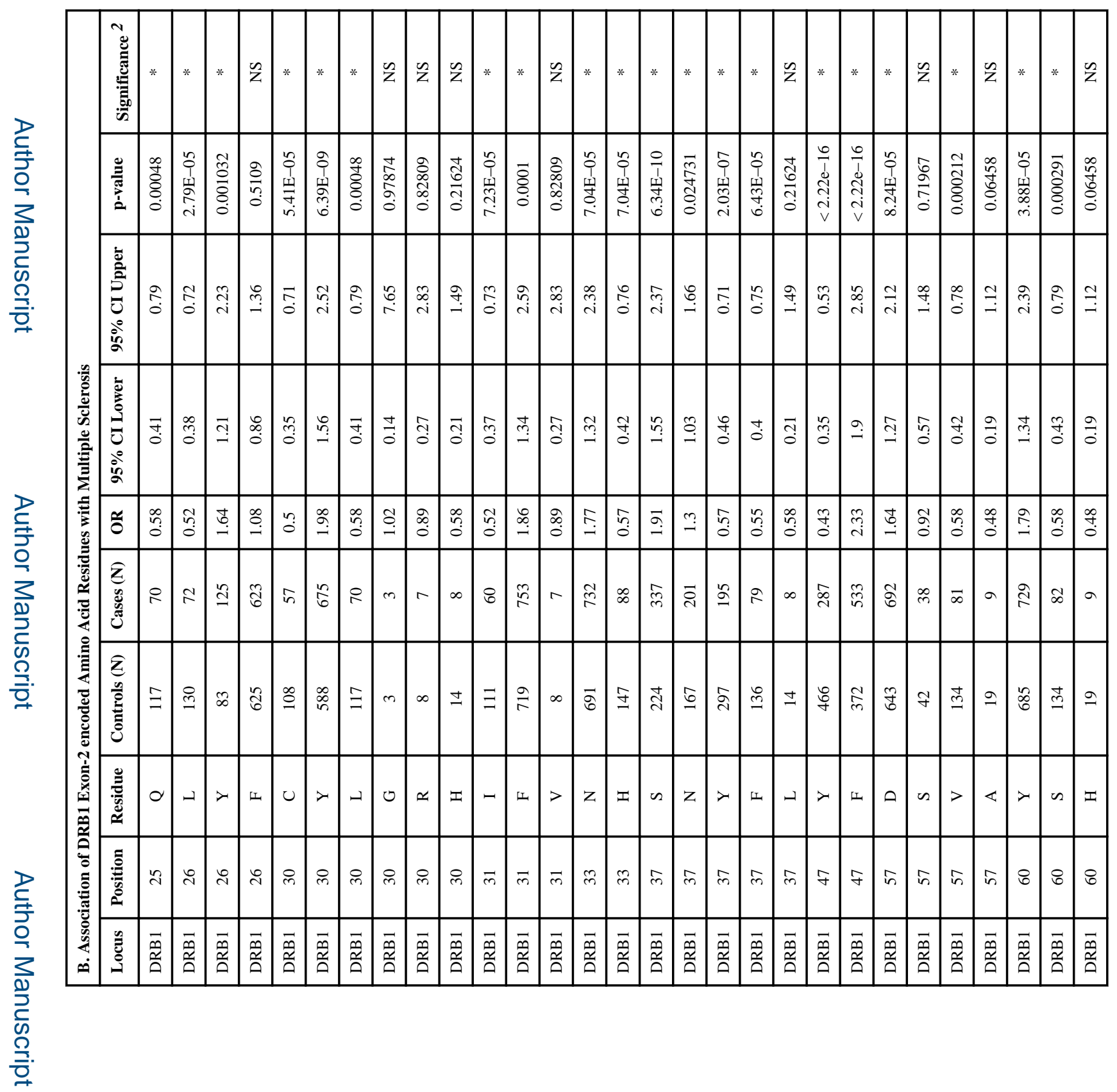

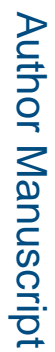



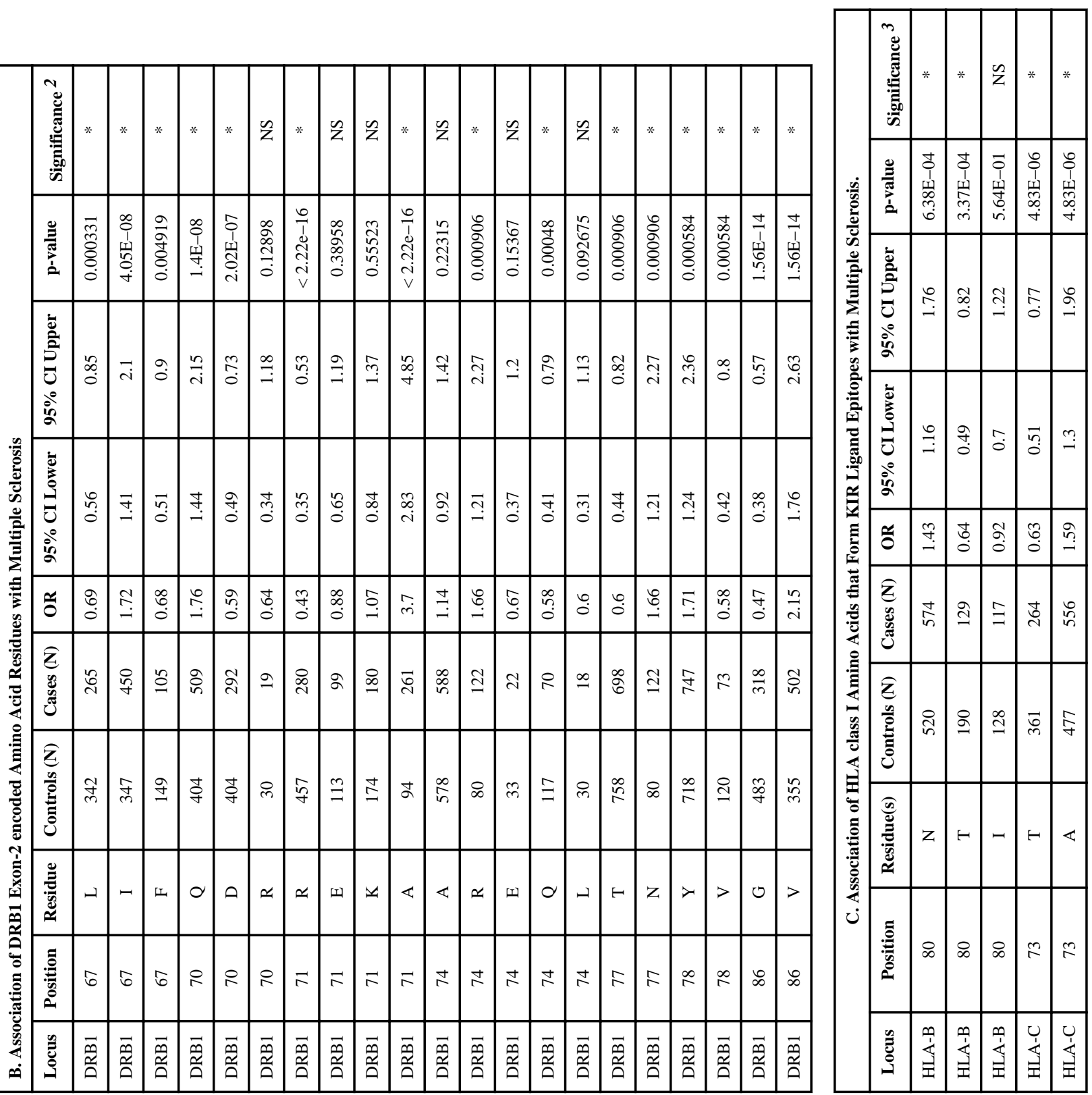

룰 


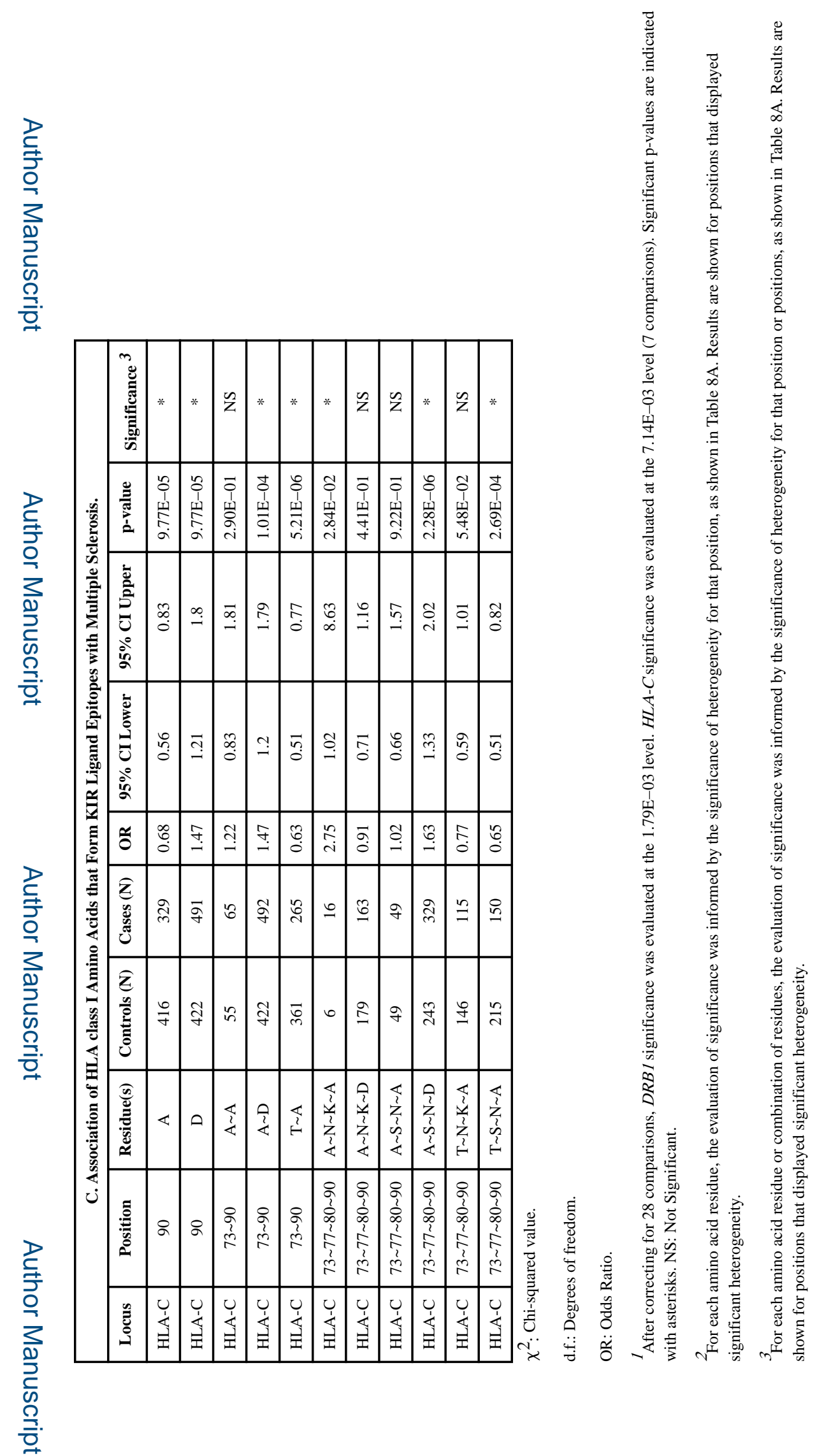

Genes Immun. Author manuscript; available in PMC 2019 April 18. 


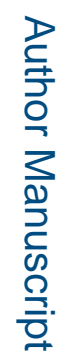

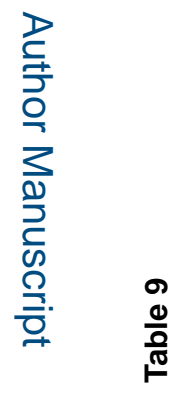
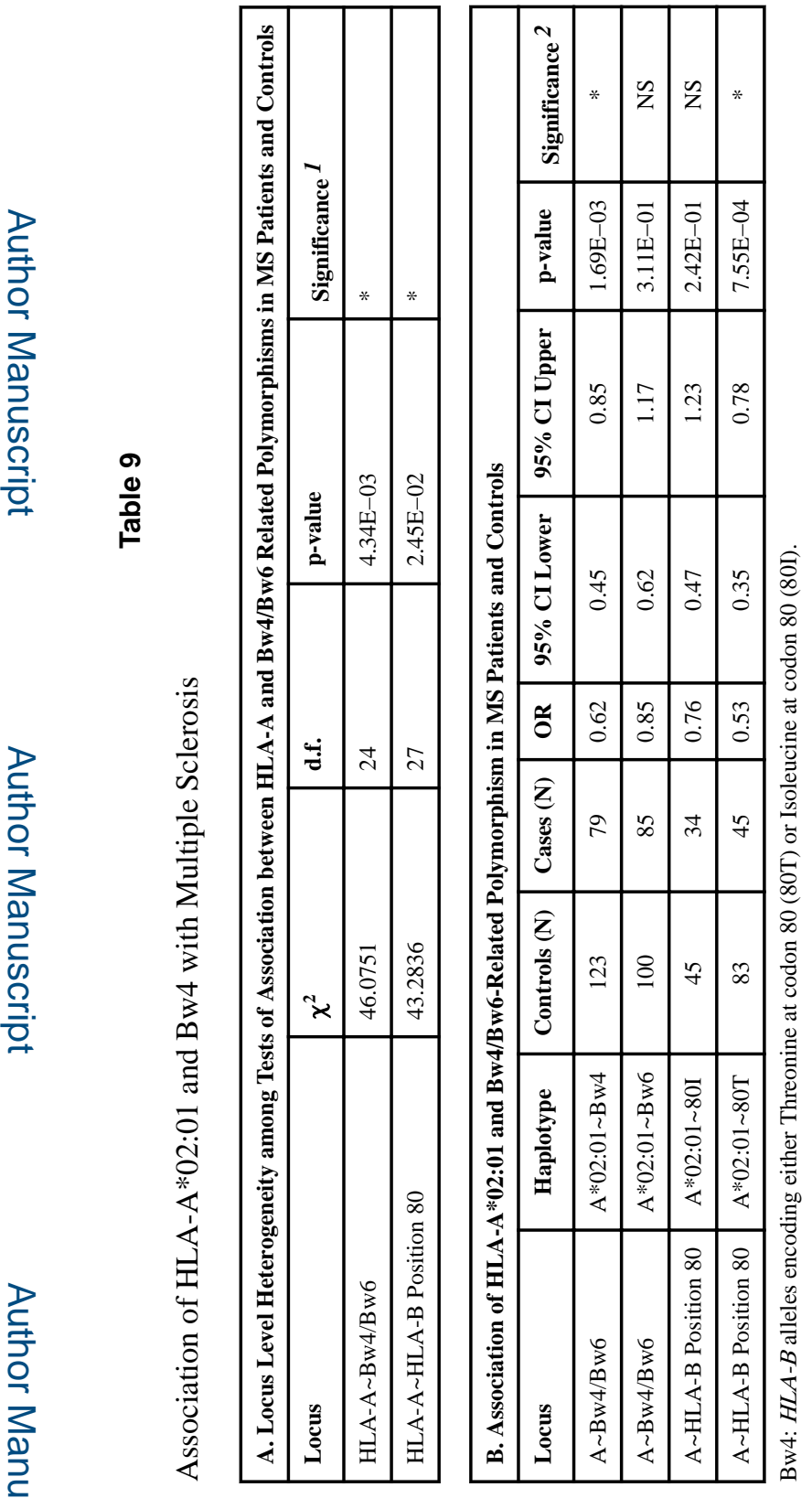

$\overline{\frac{D}{\nu}}$
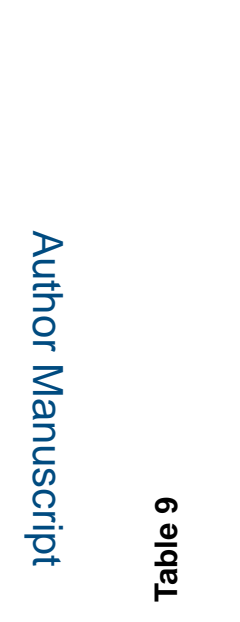

골

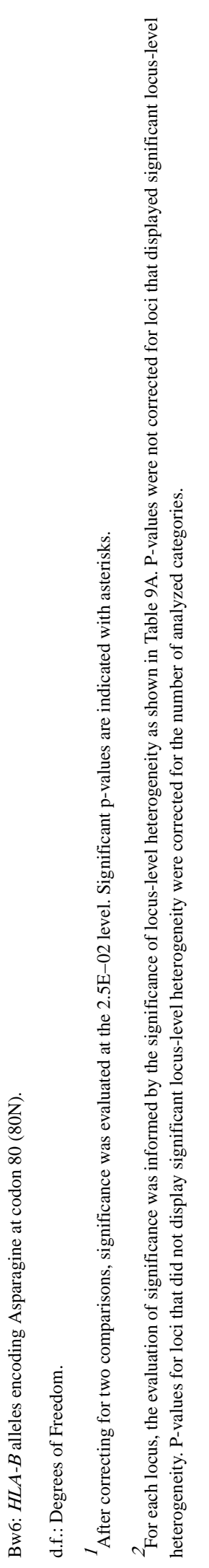

$\dot{0}$
0
0
0
0 